\title{
Molecular investigations of comets C/2002 X5 (Kudo-Fujikawa), C/2002 V1 (NEAT), and C/2006 P1 (McNaught) at small heliocentric distances ${ }^{\star}$
}

\author{
N. Biver ${ }^{1}$, D. Bockelée-Morvan ${ }^{1}$, P. Colom ${ }^{1}$, J. Crovisier ${ }^{1}$, G. Paubert ${ }^{2}$, A. Weiss ${ }^{3}$, and H. Wiesemeyer ${ }^{3}$ \\ ${ }^{1}$ LESIA, CNRS UMR 8109, UPMC, Université Paris-Diderot, Observatoire de Paris, 5 pl. Jules Janssen, 92195 Meudon, France \\ e-mail: Nicolas.Biver@obspm.fr \\ 2 IRAM, Avd. Divina Pastora, 7, 18012 Granada, Spain \\ 3 Max Planck Institute for Radio Astronomy, PO Box 20 24, 53010 Bonn, Germany \\ Received 2 December 2010 / Accepted 14 January 2011
}

ABSTRACT

\begin{abstract}
We present unique spectroscopic radio observations of comets C/2002 X5 (Kudo-Fujikawa), C/2002 V1 (NEAT), and C/2006 P1 (McNaught), which came within $r_{\mathrm{h}} \approx 0.2 \mathrm{AU}$ of the Sun in 2003 and 2007. The molecules $\mathrm{OH}, \mathrm{HCN}, \mathrm{HNC}, \mathrm{CS}$, and $\mathrm{CH}_{3} \mathrm{OH}$ were detected in each of these comets when they were exposed to strong heating from the Sun. $\mathrm{HC}_{3} \mathrm{~N}$ and $\mathrm{HCO}^{+}$were detected in comets C/2002 X5 and C/2006 P1, respectively. We show that in these very productive comets close to the Sun screening of the photodissociation by the Sun UV radiation plays a non-negligible role. Acceleration of the gas expansion velocity and day-night asymmetry is also measured and modeled. The CS photodissociation lifetime was constrained to be about $2.5 \times 10^{-5} \mathrm{~s}^{-1}$ at $r_{\mathrm{h}}=1 \mathrm{AU}$. The relative abundances are compared to values determined from more distant observations of C/2002 X5 or other comets. A high $\mathrm{HNC} / \mathrm{HCN}$ production-rate ratio, in the range $10-30 \%$ between 0.5 and $0.1 \mathrm{AU}$ from the Sun, is measured. The trend for a significant enrichment in $\mathrm{CS}$ in cometary comae $\left(\mathrm{CS} / \mathrm{HCN} \propto r_{\mathrm{h}}^{-0.8}\right)$ is confirmed in all three comets. The $\mathrm{CH}_{3} \mathrm{OH} / \mathrm{HCN}$ production rate ratio decreases at low $r_{\mathrm{h}}$. The $\mathrm{HC}_{3} \mathrm{~N} / \mathrm{HCN}$ production rate ratio in comet $\mathrm{C} / 2002 \mathrm{X} 5$ is four times higher than measured in any other comet.
\end{abstract}

Key words. comets: general - radio lines: planetary systems - submillimeter: planetary systems comets: individual: C/2002 X5 (Kudo-Fujikawa) - comets: individual: C/2002 V1 (NEAT) - comets: individual: C/2006 P1 (McNaught)

\section{Introduction}

The composition of cometary nuclei is of strong interest in understanding their origin. Having spent most of their time in a very cold environment, these objects should not have evolved much since their formation. Thus, their composition provides clues to the composition in the outer regions of the Solar Nebula where they formed. The last two decades have proven the efficiency of microwave spectroscopy in investigating the chemical composition of cometary atmospheres. About 20 different cometary molecules have now been identified at radio wavelengths (Bockelée-Morvan et al. 2004a).

In this paper, we extend our investigations of the composition of cometary atmospheres from radio observations (BockeléeMorvan et al. 2004a; Biver et al. 2002a, 2006a, 2007b) to three comets observed in 2003 and 2007. These observations were designed to measure the molecular abundances of comets approaching close to the Sun to investigate how the strength of the solar heating of both the comet nucleus and of its environment affects the coma composition. Previous observations have suggested that the relative production rates of several molecules vary with heliocentric distance (Biver et al. 2006a). The passages of comets C/2002 X5 (Kudo-Fujikawa), C/2002 V1 (NEAT), and C/2006 P1 (McNaught) provided us with the opportunity to measure molecular abundances at heliocentric distances $\left(r_{\mathrm{h}}\right)$ between 0.1 and $0.25 \mathrm{AU}$, about one order of magnitude smaller than usual. This study is complementary to the

* Tables 2-4 are only available in electronic form at http://www . aanda.org long-term monitoring of comet C/1995 O1 (Hale-Bopp) (Biver et al. 2002b), which provided information on the outgassing of a comet between 0.9 and $14 \mathrm{AU}$.

Opportunities to plan observations of comets passing within 0.2 AU from the Sun are rare. For example, comet C/1998 J1 (SOHO) was discovered too late to establish an accurate ephemeris around perihelion time. In addition, Sun-grazing comets often do not survive and even disintegrate before reaching perihelion, making observing plans extremely difficult. The last opportunity was comet C/1975 V1 (West). The observations reported here are unique, and required to develop specific observing strategies and analyses.

The organization of the paper is as follows. In Sect. 2, we present the observations of comets C/2002 X5 (Kudo-Fujikawa), C/2002 V1 (NEAT), and C/2006 P1 (McNaught) performed with the 30-m telescope of the Institut de Radioastronomie Millimétrique (IRAM) and the Nançay radio telescope. In Sects. 3 and 4, the analysis of these observations is presented. A summary follows in Sect. 5.

\section{Observations}

Owing to the late discovery or assessment of their activity, the three comets were observed as targets of opportunity using the IRAM 30-m and Nançay radio telescopes. This was possible because these telescopes do not have tight solar elongation constraints. The small solar elongation $\left(<10^{\circ}\right.$ at $\left.r_{\mathrm{h}}<0.2 \mathrm{AU}\right)$ resulted in limited observing support from other observatories. 
Table 1. Observing conditions and ephemeris errors.

\begin{tabular}{lcccccccc}
\hline \hline Comet & $\begin{array}{c}\text { UT date } \\
\text { [yyyy/mm/dd.d] }\end{array}$ & $\begin{array}{c}r_{\mathrm{h}} \\
{[\mathrm{AU}]}\end{array}$ & $\begin{array}{c}\Delta \\
{[\mathrm{AU}]}\end{array}$ & $\begin{array}{c}\text { Phase } \\
{\left[{ }^{\circ}\right]}\end{array}$ & \multicolumn{2}{c}{$O-C_{\mathrm{u}}{ }^{1}$} & \multicolumn{2}{c}{$C_{\mathrm{f}}-C_{\mathrm{u}}{ }^{1}$} \\
& $2003 / 01 / 13.6$ & 0.553 & 1.032 & 69.3 & - & - & $+1.6^{\prime \prime}$ & $-2.2^{\prime \prime}$ \\
\hline $\mathrm{C} / 2002 \mathrm{X} 5$ & $2003 / 01 / 26.5$ & 0.214 & 1.172 & 26.1 & $1.5^{\prime \prime}$ & $-11^{\prime \prime}$ & $+0.9^{\prime \prime}$ & $-10.3^{\prime \prime}$ \\
& $2003 / 03 / 12.7$ & 1.184 & 1.096 & 50.5 & - & - & $+3.0^{\prime \prime}$ & $+0.9^{\prime \prime}$ \\
$\mathrm{C} / 2002 \mathrm{~V} 1$ & $2003 / 02 / 16.6$ & 0.135 & 0.978 & 90.3 & $-1.9^{\prime \prime}$ & $-3.5^{\prime \prime}$ & $-3.9^{\prime \prime}$ & $-6.6^{\prime \prime}$ \\
& $2003 / 02 / 17.6$ & 0.107 & 0.986 & 87.7 & $-1.5^{\prime \prime}$ & $-4.5^{\prime \prime}$ & $-2.5^{\prime \prime}$ & $-8.8^{\prime \prime}$ \\
$\mathrm{C} / 2006 \mathrm{P} 1$ & $2007 / 01 / 15.6$ & 0.207 & 0.817 & 140.0 & $+1^{\prime \prime}$ & $+30^{\prime \prime}$ & $-1.2^{\prime \prime}$ & $+27.1^{\prime \prime}$ \\
& $2007 / 01 / 16.6$ & 0.229 & 0.822 & 129.3 & $+1^{\prime \prime}$ & $+28^{\prime \prime}$ & $+0.6^{\prime \prime}$ & $+25.7^{\prime \prime}$ \\
& $2007 / 01 / 17.6$ & 0.256 & 0.833 & 119.1 & $+0^{\prime \prime}$ & $+23^{\prime \prime}$ & $+2.0^{\prime \prime}$ & $+23.5^{\prime \prime}$ \\
\hline
\end{tabular}

Notes. ${ }^{(1)} O, C_{\mathrm{u}}$, and $C_{\mathrm{f}}$ denote the position of the HCN peak emission determined from mapping, the used computed ephemeris, and the final (reference) ephemeris, respectively. Orbital elements are given for C/2002 X5 (MPEC 2003-A41, 2003-A84, and 2003-D20 used, JPL\#40² reference), C/2002 V1 (MPEC 2003-C42 used, JPL\#34 reference), C/2006 P1 (JPL\#15, JPL\#25 reference). The uncertainty in reference orbit is 2". (2) JPL HORIZONS ephemerides: http://ssd.jpl .nasa.gov/?ephemerides

\subsection{C/2002 X5 (Kudo-Fujikawa)}

Comet C/2002 X5 (Kudo-Fujikawa) was discovered visually at $m_{\mathrm{v}}=9$ on 13,14 December 2002 by two Japanese amateur astronomers, T. Kudo and S. Fujikawa (Nakano 2002). At about 1.2 AU from the Earth and the Sun at that time, it was then a moderately active comet. It passed perihelion on 29 January 2003 at a perihelion distance $q=0.190$ AU from the Sun.

One of the main goals of the observations of comet C/2002 X5 at the IRAM 30-m was to measure the evolution of the $\mathrm{HNC} / \mathrm{HCN}$ production rate ratio as it approached the Sun. A first observing slot was scheduled on 4-5 January 2003, at $r_{\mathrm{h}}=$ $0.8 \mathrm{AU}$, but the weather prevented any observation. Observations performed on 13 January $\left(r_{\mathrm{h}}=0.55 \mathrm{AU}\right)$ only partly succeeded because of technical problems. Most data were acquired on 26.5 January, 2 days before perihelion, at $r_{\mathrm{h}}=0.21 \mathrm{AU}$. At that time, the comet was only observable visually by the C3 coronagraph aboard the SOlar Heliospheric Observatory (SOHO) the solar elongation was 5.5 (Bout et al. 2003; Povich et al. 2003). The pointing of the comet was a real challenge, since the ephemeris uncertainty was expected to be on the order of the beam size $\left(10-20^{\prime \prime}\right)$. Since at $r_{\mathrm{h}}=0.2$ AU molecular lifetimes are typically shorter than an hour, hence photodissociation scale lengths are smaller than the beam size, accurate pointing was required. From coarse mapping, we found the comet about $10^{\prime \prime}$ south of its predicted position (Fig. 1, Table 1). The last observing run at IRAM took place on 12 March $2003\left(r_{\mathrm{h}}=1.2 \mathrm{AU}\right.$, Fig. 3), when the comet was receding from the Sun and about 100 times less productive. A log of the observations and measured line areas are given in Table 2. Sample spectra are shown in Figs. 2-4.

To monitor the water production rate, observations of $\mathrm{OH}$ at 18-cm using the Nançay radio telescope were scheduled on a daily basis from 1 January to 10 April 2003. The $\mathrm{OH}$ lines were only detected when the comet was between 1 and 0.4 AU from the Sun, inbound and outbound.

\section{2. $\mathrm{C} / 2002$ V1 (NEAT)}

Comet C/2002 V1 (NEAT) was discovered on 6 November 2002 by the Near Earth Asteroid Tracking (NEAT) program telescope on the Haleakala summit of Maui, Hawaii (Pravdo 2002). At that time, it was a relatively faint object $\left(m_{\mathrm{v}}=17\right)$. Comet C/2002 V1 (NEAT) brightened rapidly after its discovery, becoming a potentially interesting target for observations at perihelion on 18 February 2003 at $q=0.099$ AU. The orbital period

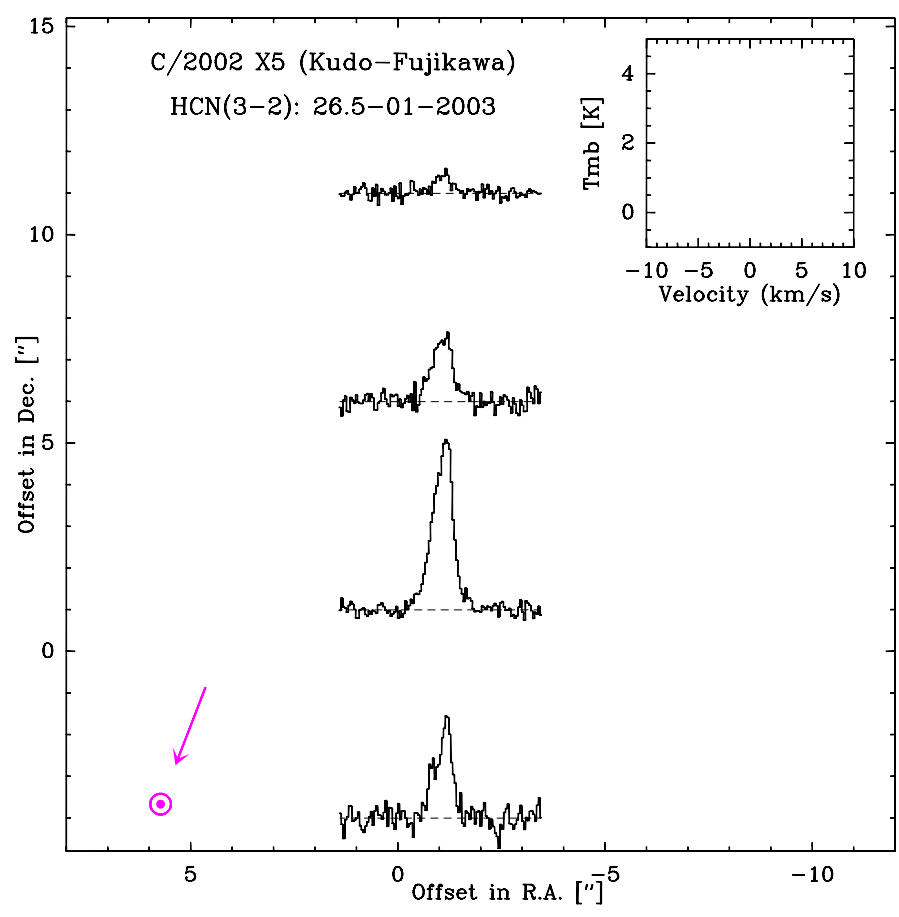

Fig. 1. Coarse map of the $\mathrm{HCN} J=3-2$ emission from comet C/2002 X5 (Kudo-Fujikawa) observed with the IRAM 30-m. Positional offsets in arcsec are with respect to the final ephemeris (Table 1). All four spectra are plotted at the same intensity and velocity scales, provided in the upper right box. The projected direction of the Sun is also given.

was estimated to be 9000 years (Nakano note NK965 ${ }^{1}$ ), suggesting that it has survived a close passage to the Sun at its previous perihelion and might be expected to do so again.

The observations at IRAM were undertaken on 16 and 17 February $2003\left(r_{\mathrm{h}}=0.13-0.11 \mathrm{AU}\right)$, i.e., just one day before perihelion. As for comet C/2002 X5 (Kudo-Fujikawa), the observations were challenging because of the lack of supporting optical astrometry, the comet being $8-6^{\circ}$ away from the Sun and only seen by the SOHO coronagraph when it became as bright as magnitudes -1 to -2 . A coarse map of the HCN $J=3-2$ line at IRAM revealed the comet to be at about 5.5" (half a beam, Fig. 5, Table 1) from its expected position. Observational data are given in Table 3.

\footnotetext{
${ }^{1}$ http://www.oaa.gr.jp/oaacs/nk/nk965.htm
} 


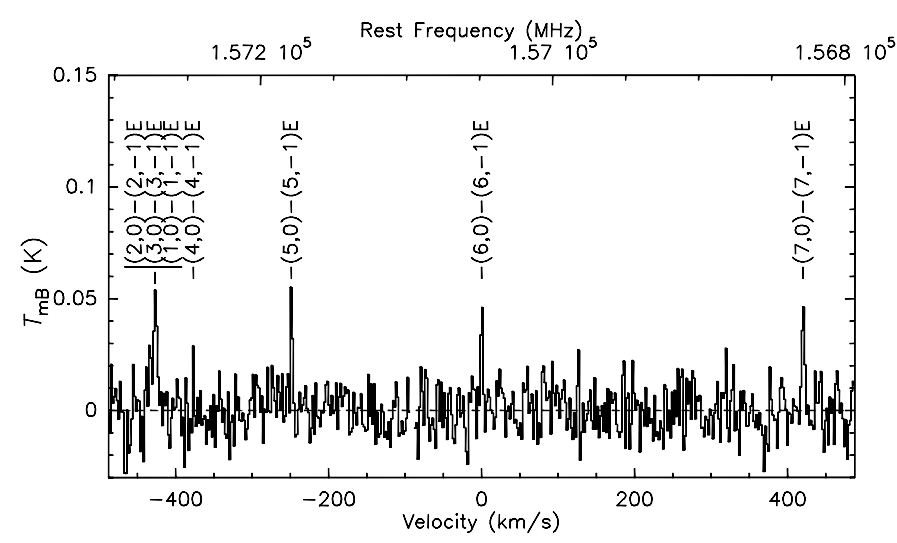

Fig. 2. $\mathrm{CH}_{3} \mathrm{OH}$ lines at $157 \mathrm{GHz}$ observed with the IRAM 30-m telescope in comet C/2002 X5 (Kudo-Fujikawa) on 26.5 January 2003. The vertical scale is main-beam brightness temperature. The horizontal scales are the rest frequency (upper scale) or the Doppler velocity in the comet rest-frame, relative to the $\left(6_{0}-6_{-1}\right) \mathrm{E}$ line frequency (bottom scale).

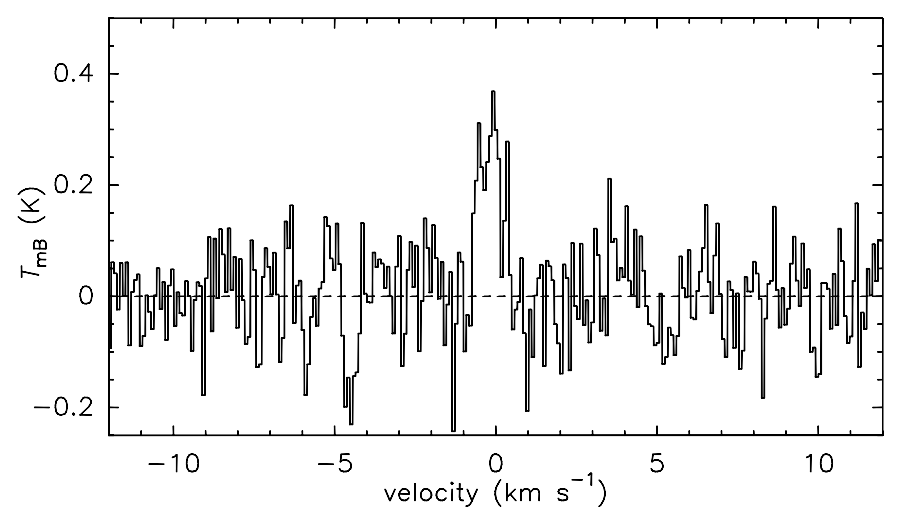

Fig. 3. HCN $J=3-2$ line observed with the IRAM 30-m telescope in comet C/2002 X5 (Kudo-Fujikawa) on 12.7 March 2003. The vertical scale is the main beam brightness temperature. The horizontal scale is the Doppler velocity in the comet rest-frame.

OH 18-cm observations were obtained nearly every day from 31 December 2002 to 25 March 2003. The comet was only detected at $r_{\mathrm{h}}>0.4 \mathrm{AU}$ from the Sun, though the water production rate $\left(Q_{\mathrm{H}_{2} \mathrm{O}}\right)$ likely exceeded $2 \times 10^{30}$ molec. s ${ }^{-1}$ at perihelion (Sect. 3).

\section{3. $C / 2006 P 1$ (McNaught)}

C/2006 P1 was discovered by Robert McNaught at $m_{\mathrm{v}}=17.3$ on 7 August 2006 (McNaught 2006) as it was at $3.1 \mathrm{AU}$ from the Sun. The geometry was very unfavorable for observing this comet as it approached the Sun. The comet was basically lost in the glare of the Sun in November and December 2006 from $r_{\mathrm{h}}=1.5$ to $0.5 \mathrm{AU}$. At $r_{\mathrm{h}}>0.5 \mathrm{AU}$, its intrinsic brightness was similar to that of comet C/1996 B2 (Hyakutake). It brightened rapidly in early January 2007 to peak at $m_{\mathrm{v}} \sim-5$ and became visible to the naked eye in broad daylight (Green 2007). It passed perihelion on 12 January 2007 at $q=0.17$ AU. Comet C/2006 P1 (McNaught) was the brightest and most productive comet since C/1965 S1 (Ikeya-Seki). The absence of an ion tail led Fulle et al. (2007) to argue that, because of a very high outgassing rate, the diamagnetic cavity was so large that ions were photodissociated before reaching the region where they could

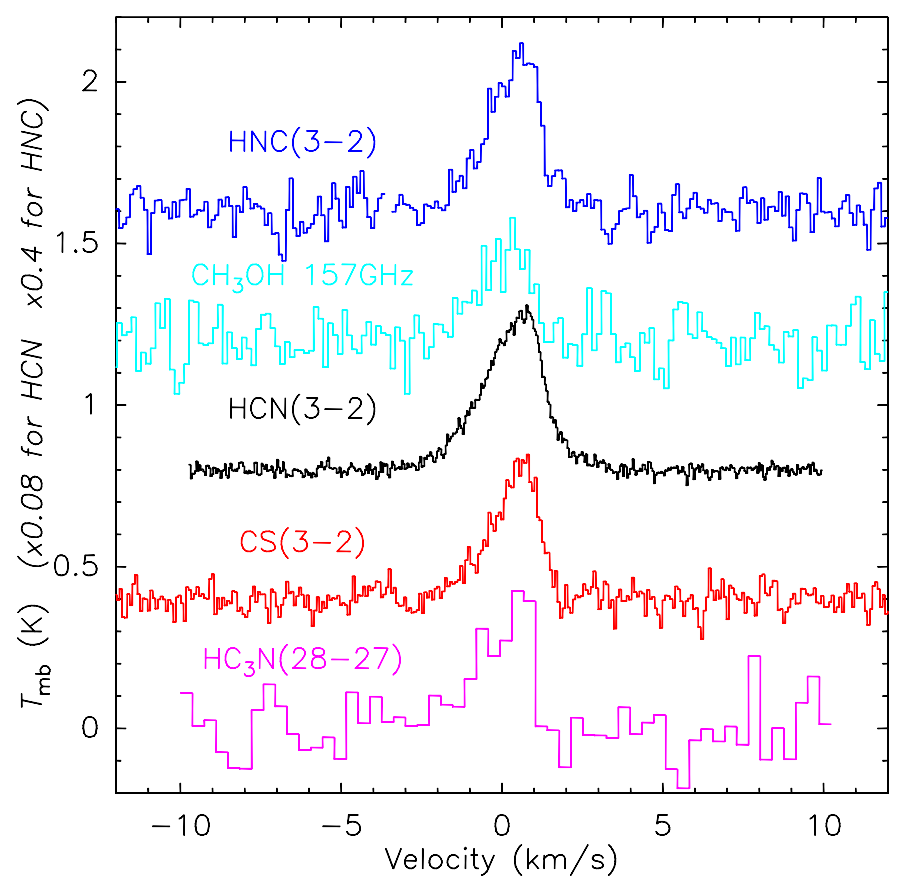

Fig. 4. $\mathrm{HC}_{3} \mathrm{~N}, \mathrm{CS}, \mathrm{HCN}, \mathrm{CH}_{3} \mathrm{OH}$ (sum of the 3 brightest lines at $157 \mathrm{GHz}$ ) and $\mathrm{HNC}$ lines observed with the IRAM 30-m telescope in comet C/2002 X5 (Kudo-Fujikawa) on 26.5 January 2003. The spectra are plotted with the same horizontal scale to compare the line widths. The intensities of the spectra of HCN and HNC were divided by 12.5 and 2.5 , respectively. Spectra are shifted vertically for clearer viewing.

interact with the solar wind. A week after perihelion, C/2006 P1 displayed a fantastic dust tail with many striae curving around $1 / 3$ of sky at a mean distance of $20^{\circ}$ from the Sun.

The IRAM observations were performed on 15, 16, and 17 January 2007 ( $\left.r_{\mathrm{h}}=0.21-0.25 \mathrm{AU}\right)$. The comet ephemeris was expected to be possibly wrong by up to $1^{\prime}$ (corresponding to the 3- $\sigma$ uncertainty from the JPL's HORIZONS ephemeris, Giorgini et al. 1996). An on-the-fly map of the HCN J(3-2) line on 15.6 January UT with the IRAM 30-m HERA array of receivers showed that the comet was $30^{\prime \prime}$ north of its predicted position (Fig. 7). Orbit updates later confirmed the observed offset (Table 1). Most observations consisted of five-point integrations at 0 and $6^{\prime \prime}$ offsets in RA and Dec to pinpoint the maximum emission (e.g., Fig. 9). On 17.5 January, the observations were affected by strong anomalous refraction due to the low elevation of the comet $\left(21-17^{\circ}\right)$. The effect was estimated to be equivalent to a mean pointing offset of up to $12^{\prime \prime}$, implying a loss of $90 \%$ of the signal. Observational data are summarized in Table 4.

$\mathrm{OH} 18-\mathrm{cm}$ observations were performed daily between 10 and 20 January. The comet was detected intermittently. $\mathrm{OH}$ $18-\mathrm{cm}$ lines had never been detected that close to the Sun (0.17 AU) in a comet before.

\section{Analysis of Nançay data $-\mathrm{H}_{2} \mathrm{O}$ production rates}

The characteristics of the Nançay radio telescope and the $\mathrm{OH}$ observations of comets may be found in Crovisier et al. (2002). The $\mathrm{OH} 18-\mathrm{cm}$ lines usually observed in comets are maser lines pumped by UV solar radiation (Despois et al. 1981). However, for high water-production rates, the maser emission is quenched by collisions in a large part of the coma, and most of the signal may originate from thermal emission. The radius of the region where the maser emission is quenched is estimated to be 


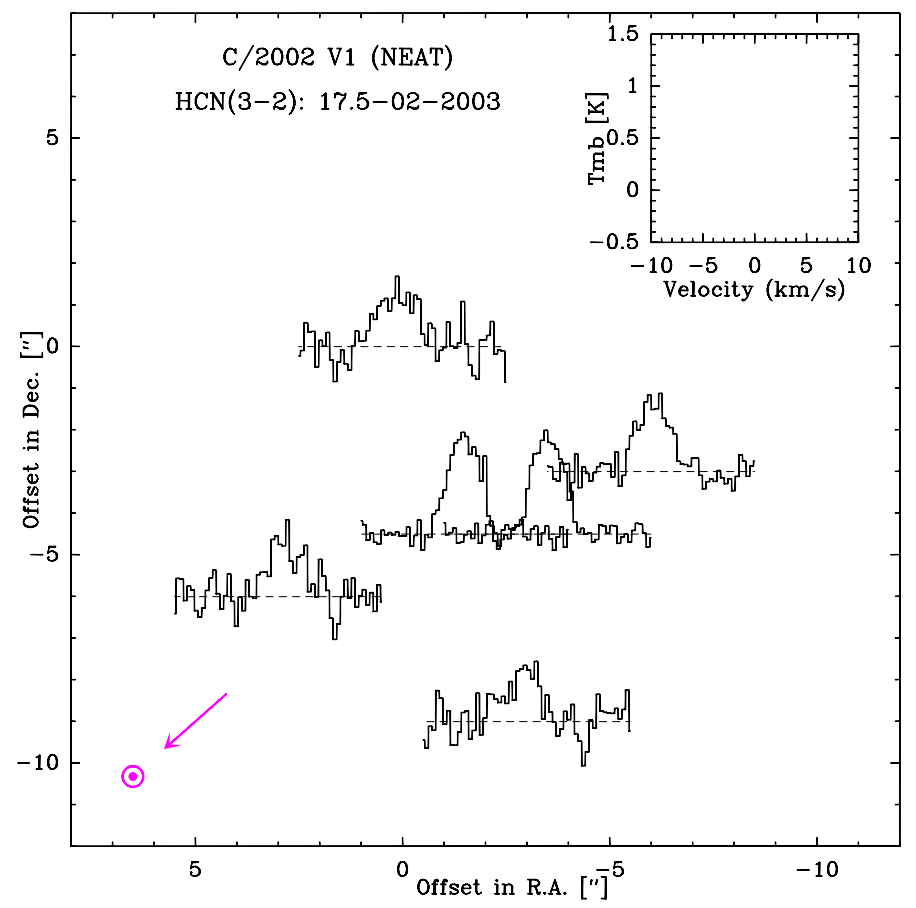

Fig. 5. Scales as in Fig. 1: coarse map of the HCN $J=3-2$ emission in comet C/2002 V1 (NEAT) with the IRAM 30-m on 17.5 February 2003. But in this case, spectra are plotted at positions relative to the ephemerides used during the observations.

$50000 r_{\mathrm{h}} \sqrt{Q_{29}} \mathrm{~km}$, where $Q_{29}$ is the water production rate in units of $10^{29}$ molec. $\mathrm{s}^{-1}$ (Gérard et al. 1998). For production rates above $6 \times 10^{29}$ molec. $\mathrm{s}^{-1}$ and the heliocentric distances where the comets were observed $\left(r_{\mathrm{h}}<0.3 \mathrm{AU}\right)$, most $\mathrm{OH}$ radicals dissociate within the quenching zone. Hence, the signal is dominated by $\mathrm{OH}$ thermal emission. The $\mathrm{OH}$ production rates or upper limits are given in Table 5 and sample spectra are provided in Fig. 11.

Table 5 also includes water-production rate measurements from other instruments for comet $\mathrm{C} / 2002$ X5. The $\mathrm{H}_{2} \mathrm{O}$ line at $557 \mathrm{GHz}$ was observed in this comet with Odin during March 2003 (Biver et al. 2007a). Observations were conducted with the SOHO coronagraph spectrometer on the perihelion date: from $\mathrm{H}$ Lyman $\alpha$ measurements, the peak outgassing rate of water is estimated to $\sim 3 \times 10^{30}$ molec. $\mathrm{s}^{-1}$ (Combi et al. 2008). According to Povich et al. (2003) and Bout et al. (2003), this comet displayed a strongly variable activity around perihelion with a $\sim$ two day period. During the perihelion period, the comet was not or only very marginally detected at Nançay. Averaging the data obtained during the five days around perihelion, we obtain a possible 4- $\sigma$ detection (subject to baseline uncertainties) suggesting a production rate of $\sim 6 \times 10^{30}$ molec. $s^{-1}$ (Table 5). This is higher than the SOHO estimate, but still within the same order of magnitude. Power laws fitted to Nançay and Odin data (Fig. 18) yield values in the same range $1.5-5.4 \times 10^{30}$ molec. $\mathrm{s}^{-1}$ at $0.214 \mathrm{AU}$ from the Sun. A mean value of $3.5 \times 10^{30}$ molec. $\mathrm{s}^{-1}$ is adopted.

For C/2002 V1 (NEAT), the pre-perihelion observations can be fitted by a power law $\left(0.33 \pm 0.03 \times 10^{29} \times r_{\mathrm{h}}^{-1.95 \pm 0.23}\right)$, which extrapolates to $Q_{\mathrm{H}_{2} \mathrm{O}}=1.6 \times 10^{30}$ and $2.5 \times 10^{30}$ molec. $\mathrm{s}^{-1}$ for 16 and 17 January 2003, respectively, consistent with the upper limit determined for these days. Extrapolation of SOHOSWAN measurements yield values that are four times higher but indicative of abundances relative to water that are abnormaly low for all molecules. We assume that $Q_{\mathrm{H}_{2} \mathrm{O}}=2.0$ and

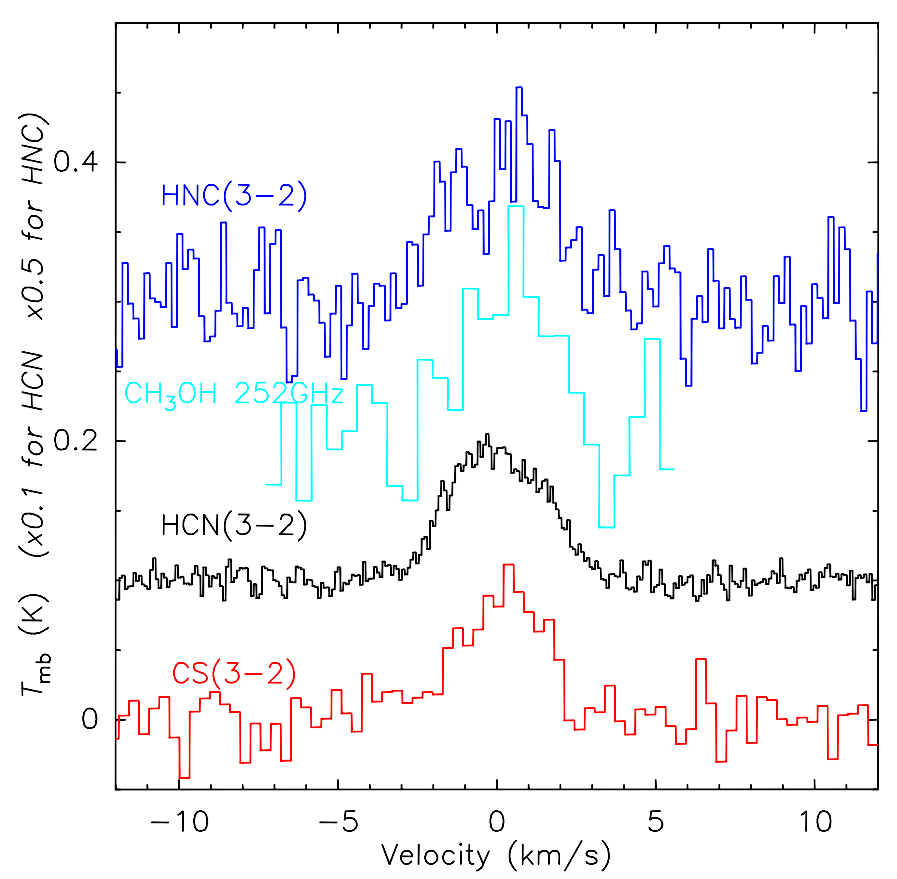

Fig. 6. $\mathrm{CS}, \mathrm{HCN}, \mathrm{CH}_{3} \mathrm{OH}$ (sum of the 8 brightest lines at $252 \mathrm{GHz}$ ), and HNC lines observed with the IRAM $30-\mathrm{m}$ telescope in comet C/2002 V1 (NEAT) on 16.5-17.6 February 2003. The spectra are plotted with the same horizontal scale to compare the line widths. The intensities of the spectra of $\mathrm{HCN}$ and $\mathrm{HNC}$ were divided by 10 and 2, respectively. Spectra are shifted vertically for clearer viewing.

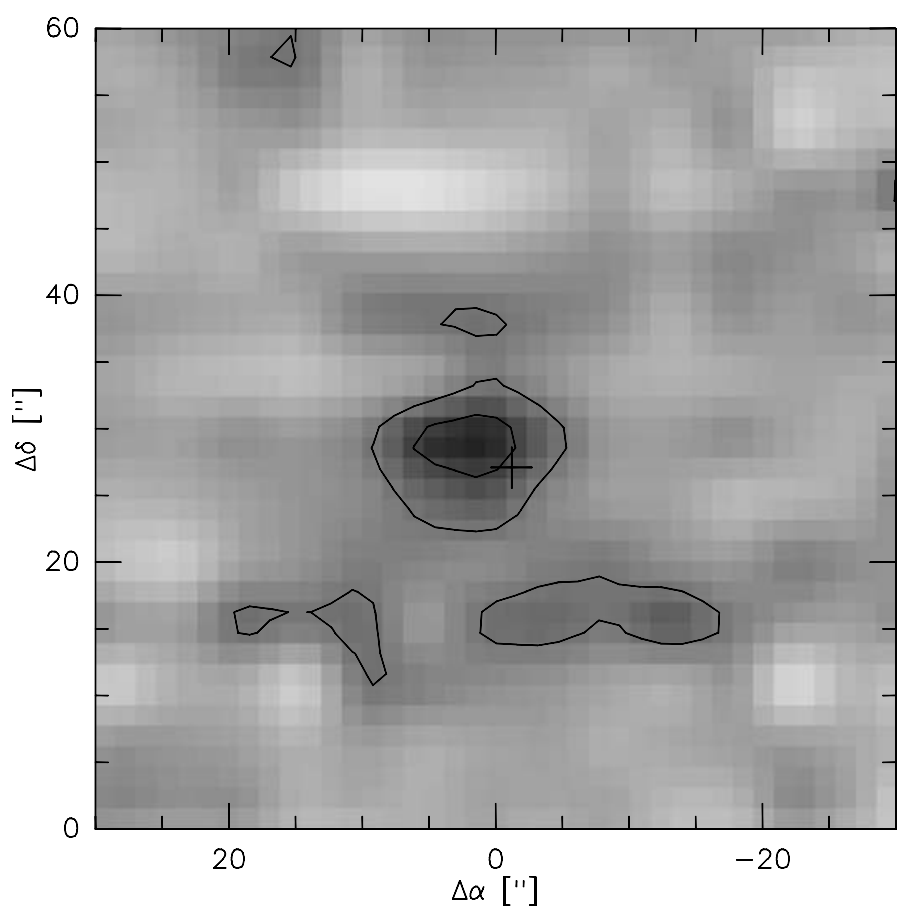

Fig. 7. On-the-fly map of the $\mathrm{HCN} J=3-2$ emission in comet C/2006 P1 (McNaught) obtained with the IRAM 30-m on 15.65 January 2007 (4 min integration time). The de-pixelized image shows the line area between -3 and $+3 \mathrm{~km} \mathrm{~s}^{-1}$, contour levels are 2 and $4 \sigma_{\text {rms }}$. The cross marks the comet position as computed from the reference ephemeris. Before gridding to beam/2 sampling, a linear spatial baseline was subtracted from each on-the-fly subscan to remove total power fluctuations of mainly atmospheric orgin. 


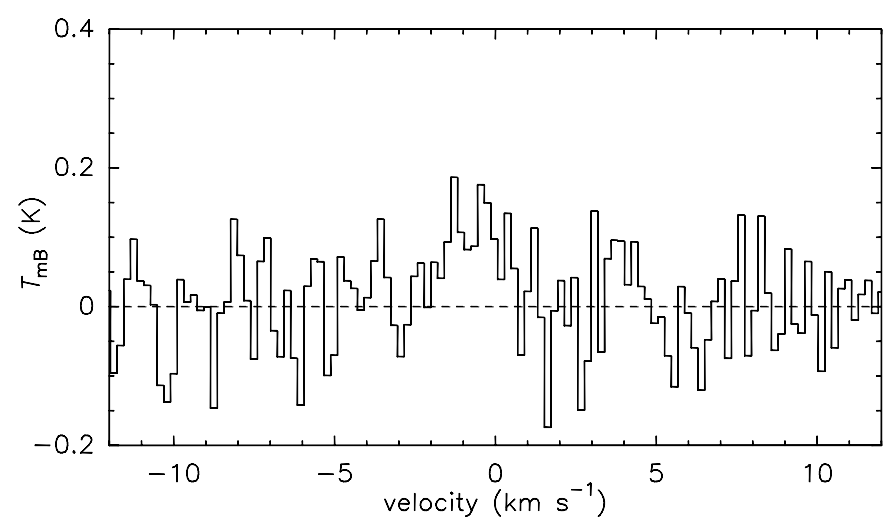

Fig. 8. HDO line at $225.896 \mathrm{GHz}$ observed with the IRAM 30-m telescope in comet C/2006 P1 on 16.6 January 2007. The vertical scale is the main-beam brightness temperature. The horizontal scale is the Doppler velocity in the comet rest-frame.

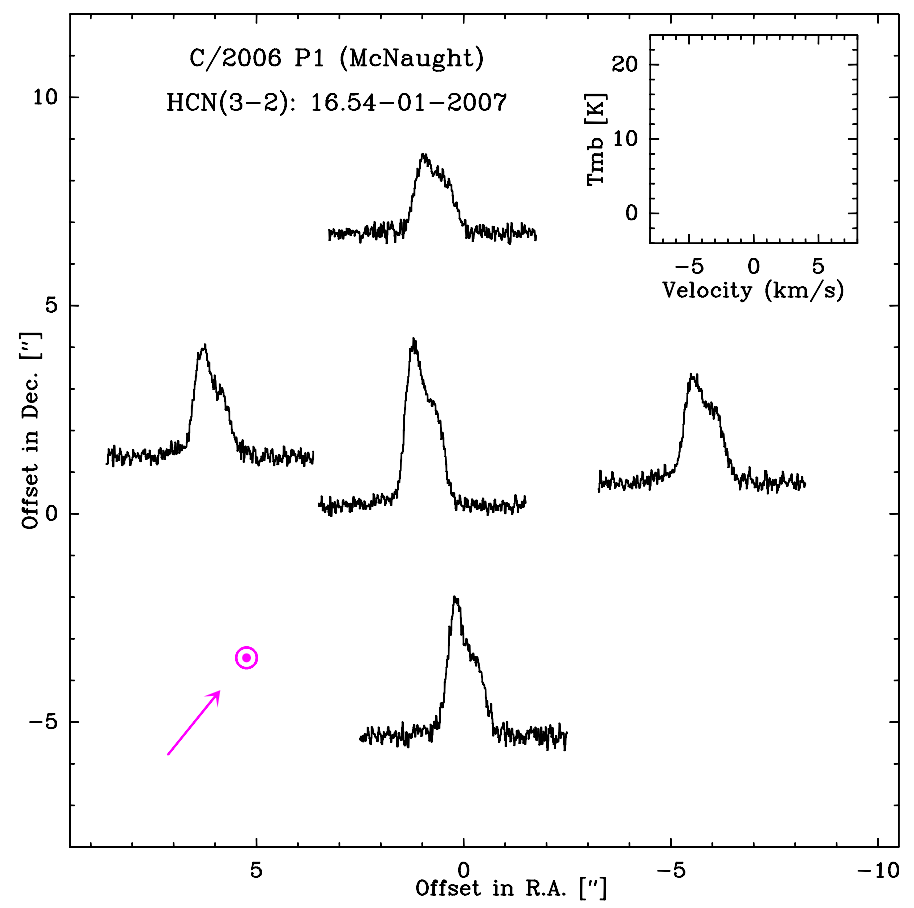

Fig. 9. Coarse map of the HCN J(3-2) emission from comet C/2006 P1 (McNaught) on 16.5 January 2007, displayed as in Figs. 1 and 5, with positions relative to the final ephemerides (Table 1).

$2.5 \times 10^{30}$ molec. $\mathrm{s}^{-1}$, respectively, these values being more compatible with the day-to-day variations observed in millimeter spectra of other molecules.

As for C/2006 P1 (McNaught), the water production rates for 13 and 19 January deduced from the Nançay data agree with the estimated HDO production rate from the marginally detected line at $225.9 \mathrm{GHz}$ (Fig. 8) and the $\mathrm{HDO} / \mathrm{H}_{2} \mathrm{O}=6 \times 10^{-4}$ ratio measured in comets. The total production rate varied from $\approx 40 \times$ $10^{30}$ down to $\approx 5 \times 10^{30}$ molec. $\mathrm{s}^{-1}$ at that time (Sect. 3 ).

The estimated visual magnitudes of these comets at perihelion were $m_{1} \approx+3, m_{1} \approx-1.5$, and $m_{1} \approx-5$ for C/2002 X5, C/2002 V1, and C/2006 P1, respectively. Correcting for the -2 mag surge in brightness of C/2006 P1 caused by forward scattering (Marcus 2007), and using the correlation law between heliocentric magnitude and $Q_{\mathrm{H}_{2} \mathrm{O}}$ of Jorda et al. (2008), this would imply water production rates of 1,11 , and

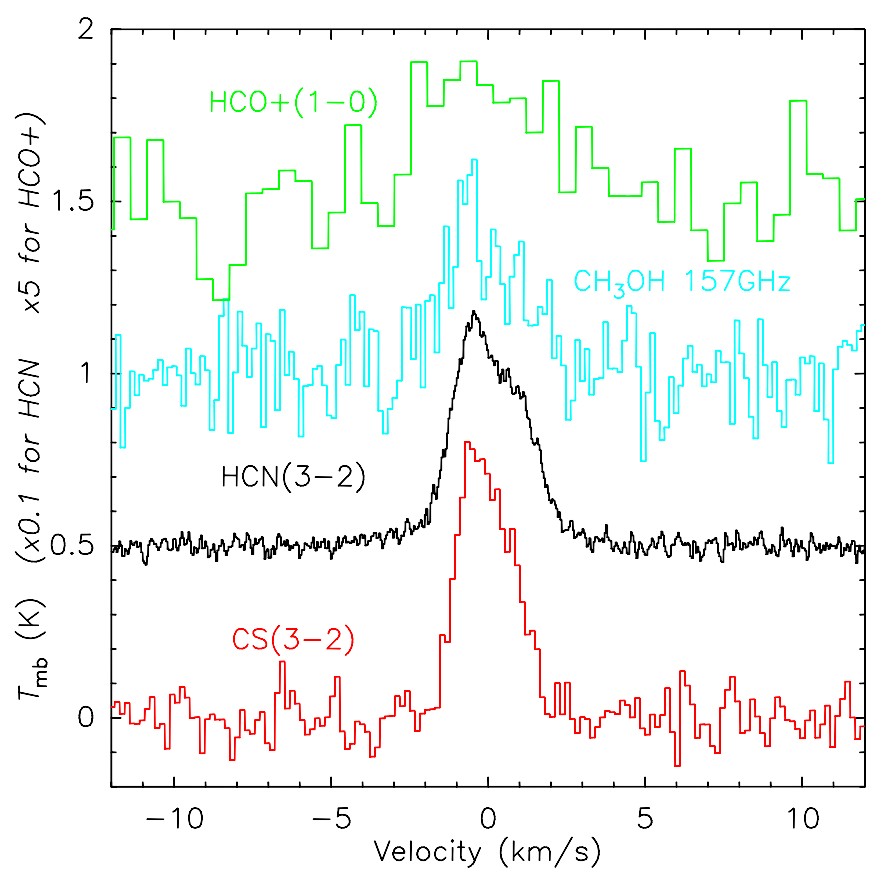

Fig. 10. $\mathrm{CS}, \mathrm{HCN}, \mathrm{CH}_{3} \mathrm{OH}$ (sum of the 4 brightest lines at $157 \mathrm{GHz}$ ), and HNC lines observed with the IRAM 30-m telescope in comet C/2006 P1 (McNaught) on 16.5 or 17.6 January 2007. Spectra have been plotted at the same horizontal scale to compare the line widths. The intensity scale is reduced by 10 and 2 for HCN and HNC, respectively, and shifted vertically for better viewing.

$26 \times 10^{30}$ molec. $\mathrm{s}^{-1}$ respectively. The comparison to measured production rates in Table 5 suggests that $\mathrm{C} / 2002 \mathrm{~V} 1$ was a more dusty comet than the two others since, unlike C/2002 X5 and $\mathrm{C} / 2006 \mathrm{P} 1$, the actual outgassing rate being much lower than the value $\left(11 \times 10^{30}\right.$ molec. $\left.\mathrm{s}^{-1}\right)$ inferred from visual magnitudes.

\section{Analysis of IRAM data}

Molecular production rates were derived using models of molecular excitation and radiation transfer (Biver et al. 1999, 2000, 2006a). The excitation model of $\mathrm{CH}_{3} \mathrm{OH}$ was updated. The computation of the partition function considers now the first torsional state, which is populated significantly in the hot atmospheres of the comets studied in this paper. For these productive comets observed at small $r_{\mathrm{h}}$, a significant fraction of the observed molecules are photodissociated before leaving the collision-dominated region. Thus, the determination of the gas kinetic temperature (which controls the rotational level populations in the collision zone) and strong constraints on molecular lifetimes were essential. As shown below, line shapes and brightness distributions obtained from coarse maps provide information on the gas outflow velocity and molecular lifetimes.

\subsection{Gas temperature}

Table 6 summarizes rotational temperatures deduced from relative line intensities. Using our excitation models, we then constrained the gas temperature (Table 6) following the methods outlined in, e.g., Biver et al. (1999). Several data are indicative of relatively high temperatures, which are difficult to measure because the rotational population is spread over many levels making individual lines weaker. Hence, the uncertainties in derived values are high. We note that the values derived for C/2002 X5 

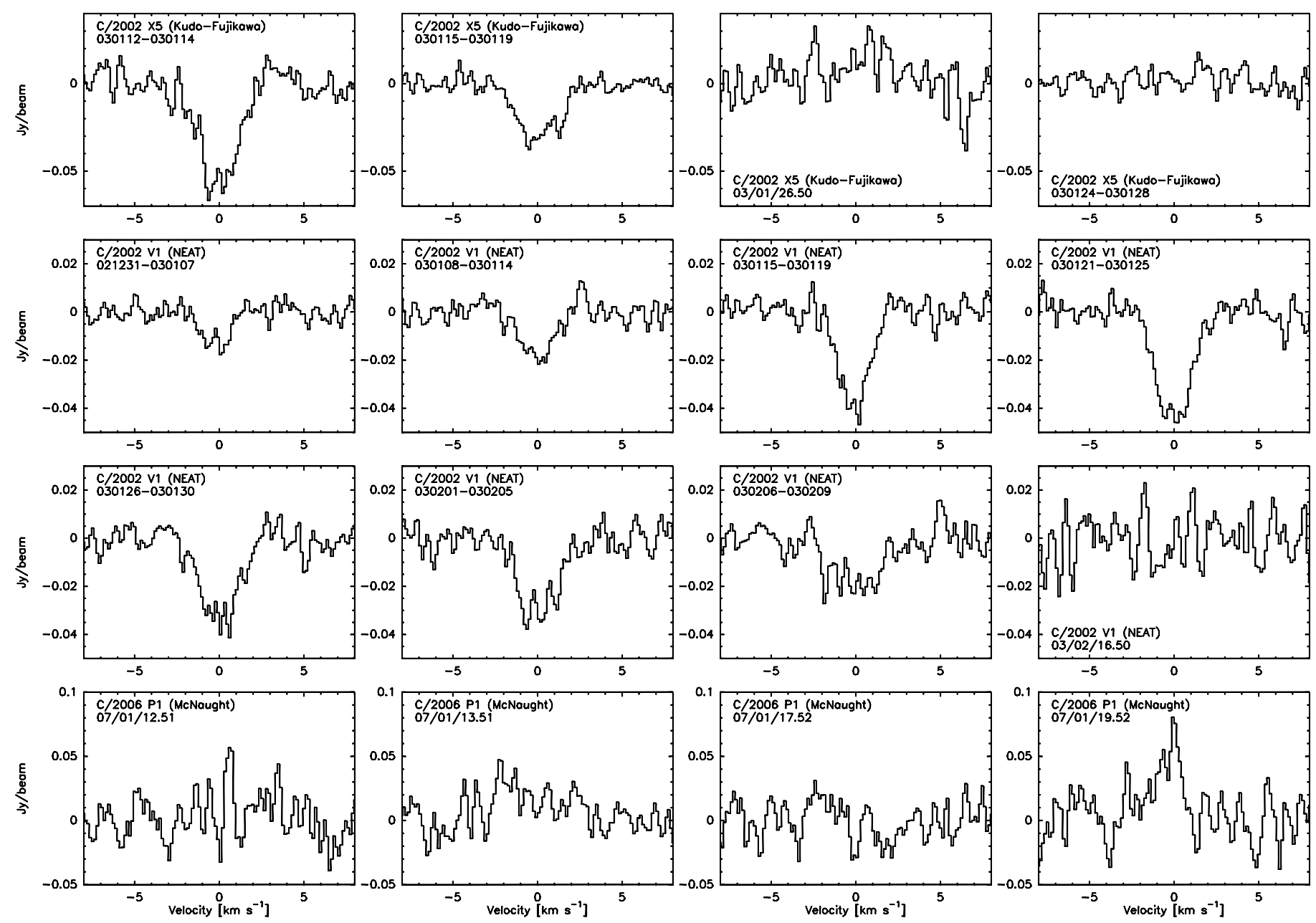

Fig. 11. Nançay spectra of $\mathrm{OH}$ 18-cm lines (average of 1665 and $1667 \mathrm{MHz}$ transitions) corresponding to observations listed in Table 5.

from $\mathrm{CH}_{3} \mathrm{OH}$ lines do not reflect the marginal detection of some lines. The inconsistency between the different measurements, especially from $\mathrm{CH}_{3} \mathrm{OH}$ and $\mathrm{HCN}$ lines in comet $\mathrm{C} / 2006 \mathrm{P} 1$, is possibly related to differences in collision cross-sections and temperature variations in the coma.

Gas temperature laws as a function $r_{\mathrm{h}}$ were obtained for comets C/1995 O1 (Hale-Bopp) (Biver et al. 2002b), C/1996 B2 (Hyakutake) (Biver et al. 1999), and 153P/Ikeya-Zhang (Biver et al. 2006a). The laws (100r $r_{\mathrm{h}}^{-1.1}$ for Hale-Bopp and $60 r_{\mathrm{h}}^{-0.9}$ for other comets on average), extrapolate to $T=200-1000 \mathrm{~K}$ for $r_{\mathrm{h}}=0.25-0.11$ AU. Photolytic heating increases with decreasing $r_{\mathrm{h}}$ and the increasing production rate of water. Hence, we expect higher temperatures for the most productive comet C/2006 P1. Combi \& Smyth (1988) predicted a maximum temperature on the order of 500-900 K for comet Kohoutek at 0.25-0.14 AU, but temperatures are generally below $300 \mathrm{~K}$ at distances from the nucleus where molecules are not photodissociated. Given also that the $\mathrm{HCN} J(3-2) v_{2}=1$ line at $265852.709 \mathrm{MHz}$ is not detected, we estimate that temperatures are lower than $300 \mathrm{~K}$ below $r_{\mathrm{h}}=0.25 \mathrm{AU}$.

For $\mathrm{C} / 2002 \mathrm{X} 5$, we adopted the gas kinetic temperature values of $50 \mathrm{~K}, 180 \mathrm{~K}$, and $40 \mathrm{~K}$ for mid-January, end of January, and mid-March all in 2003, respectively. For C/2002 V1 and $\mathrm{C} / 2006 \mathrm{P} 1$, we used $150 \mathrm{~K}$ and $300 \mathrm{~K}$, respectively. We later discuss (in Sect. 5.1) the influence of the assumed temperature on the inferred production rates.

\subsection{Screening of photolysis by water molecules}

Given high water-production rates $\left(>10^{30}-10^{31}\right.$ molec. $\left.\mathrm{s}^{-1}\right)$, self-shielding against photodissociation by solar UV radiation is significant for these comets. As a consequence, molecules can have longer lifetimes on the night side, and reduced $\mathrm{H}_{2} \mathrm{O}$ photolysis may limit gas acceleration. We studied the screening of photolysis using simplified assumptions: isotropic outgassing at a constant expansion velocity and an infinite lifetime for the screening molecules (i.e., we assumed that their scale length is larger than the size of the optically thick region). According to Nee \& Lee (1985), when considering Lee \& Suto (1986) and Lee (1984), the OH photoabsorption cross-section does not differ much from the $\mathrm{H}_{2} \mathrm{O}$ one: it peaks close to the Lyman $\alpha$ wavelength and is slightly stronger (1-2 times). On the other hand, the cometary hydrogen may not absorb significantly the Solar Lyman $\alpha$ spectral line. The comet Lyman $\alpha$ line is too narrow (velocity dispersion of $20 \mathrm{~km} \mathrm{~s}^{-1}$ ) to absorb significantly the solar emission $\left(\approx 180 \mathrm{~km} \mathrm{~s}^{-1}\right.$ line width). Consequently, if the sum of the scalelengths of $\mathrm{H}_{2} \mathrm{O}$ and $\mathrm{OH}$ is larger than the distances from the nucleus considered hereafter, the infinite lifetime assumption should not underestimate the screening effect.

In cylindrical coordinates, with the vertical $z$-axis pointing towards the Sun, a point in the coma has coordinates $\left(\theta, \rho=r \sin (\phi), z_{r}=r \cos (\phi)\right)$, where $r$ is the distance to the nucleus and $\phi$ the co-latitude angle. The photodissociation rate of a molecule $\mathrm{M}$, characterized by its photodissociation 
Table 5. Water production rates.

\begin{tabular}{|c|c|c|c|c|c|}
\hline $\begin{array}{l}\text { UT date } \\
\text { [mm/dd.dd] }\end{array}$ & $\begin{array}{l}\left\langle r_{\mathrm{h}}\right\rangle \\
{[\mathrm{AU}]}\end{array}$ & $\begin{array}{l}\text { Observatory } \\
\text { and line }\end{array}$ & $\begin{array}{l}\text { Line intensity } \\
{\left[\mathrm{mJy} \mathrm{km} \mathrm{s}^{-1}\right]}\end{array}$ & $\begin{array}{c}Q_{\mathrm{H}_{2} \mathrm{O}} \\
{\left[\text { [molec. } \mathrm{s}^{-1}\right]}\end{array}$ & Ref. \\
\hline \multicolumn{6}{|c|}{ C/2002 X5 (Kudo-Fujikawa): (2003) } \\
\hline $01 / 12.5-14.5$ & 0.55 & Nançay OH $18-\mathrm{cm}$ & $-156 \pm 7$ & $1.5 \pm 0.1 \times 10^{29}$ & \\
\hline $01 / 15.5-19.5$ & 0.45 & Nançay OH 18-cm & $-91 \pm 5$ & $1.8 \pm 0.1 \times 10^{29}$ & \\
\hline $01 / 26.50$ & 0.214 & Nançay OH 18-cm & $47 \pm 15$ & $85 \pm 27 \times 10^{29}$ & \\
\hline $01 / 25.5-30.5$ & 0.205 & Nançay OH $18-\mathrm{cm}$ & $\approx 32 \pm 8$ & $\approx 64 \pm 16 \times 10^{29}$ & \\
\hline 01-02 & $<1$ & SOHO-SWAN & - & $0.56 \times 10^{29} \times r_{\mathrm{h}}^{-2.0}$ & [3] \\
\hline $01 / 27.92$ & 0.195 & SOHO-UVCS Lyman $\alpha$ & - & $5.5 \times 10^{29}$ & [1] \\
\hline $01 / 28.13$ & 0.194 & SOHO-UVCS Lyman $\alpha$ & - & $9.0 \times 10^{29}$ & [1] \\
\hline $01 / 28.79$ & 0.190 & SOHO-UVCS Lyman $\alpha$ & - & $13.0 \times 10^{29}$ & [1] \\
\hline $01 / 29.17$ & 0.190 & SOHO-UVCS Lyman $\alpha$ & - & $27.0 \times 10^{29}$ & [1] \\
\hline $03 / 12.5$ & 1.178 & Odin $\mathrm{H}_{2} \mathrm{O} 557 \mathrm{GHz}$ & $879 \pm 79^{1}$ & $0.21 \pm 0.01 \times 10^{29}$ & [2] \\
\hline \multicolumn{6}{|c|}{ C/2002 V1 (NEAT): (2003) } \\
\hline 01/00-07 & 1.30 & Nançay OH 18-cm & $-25 \pm 4$ & $0.15 \pm 0.02 \times 10^{29}$ & \\
\hline $01 / 08-14$ & 1.15 & Nançay OH $18-\mathrm{cm}$ & $-45 \pm 4$ & $0.24 \pm 0.02 \times 10^{29}$ & \\
\hline 01/15-19 & 1.01 & Nançay OH 18-cm & $-81 \pm 5$ & $0.46 \pm 0.03 \times 10^{29}$ & \\
\hline $01 / 21-25$ & 0.87 & Nançay OH $18-\mathrm{cm}$ & $-110 \pm 6$ & $0.55 \pm 0.03 \times 10^{29}$ & \\
\hline $01 / 26-30$ & 0.73 & Nançay OH 18-cm & $-93 \pm 5$ & $0.59 \pm 0.03 \times 10^{29}$ & \\
\hline $02 / 01-05$ & 0.59 & Nançay OH 18-cm & $-85 \pm 6$ & $0.70 \pm 0.06 \times 10^{29}$ & \\
\hline 02/06-09 & 0.45 & Nançay OH 18-cm & $-66 \pm 7$ & $1.7 \pm 0.2 \times 10^{29}$ & \\
\hline $02 / 16.50$ & 0.136 & Nançay OH 18-cm & $-2 \pm 13$ & $<150 \times 10^{29}$ & \\
\hline $01-03$ & $<1$ & SOHO-SWAN & - & $0.94 \times 10^{29} \times r_{\mathrm{h}}^{-2.1}$ & [3] \\
\hline \multicolumn{6}{|c|}{ C/2006 P1 (McNaught): (2007) } \\
\hline $01 / 12.51$ & 0.171 & Nançay OH 18-cm & $45 \pm 23$ & $<270 \times 10^{29}$ & \\
\hline $01 / 13.51$ & 0.173 & Nançay OH 18-cm & $111 \pm 15$ & $400 \pm 60 \times 10^{29}$ & \\
\hline $01 / 17.52$ & 0.254 & Nançay OH $18-c m$ & $-9 \pm 23$ & $<100 \times 10^{29}$ & \\
\hline $01 / 19.52$ & 0.311 & Nançay OH 18-cm & $128 \pm 26$ & $80 \pm 20 \times 10^{29}$ & \\
\hline
\end{tabular}

Notes. ${ }^{(1)}$ Line integrated intensity in $\mathrm{mK} \mathrm{km} \mathrm{s}^{-1}$.

References. [1]: Povich et al. (2003); [2]: Biver et al. (2007a); [3]: Combi et al. (2008).

Table 6. Gas temperature measurements.

\begin{tabular}{|c|c|c|c|c|c|}
\hline $\begin{array}{c}\text { UT date } \\
\text { [mm/dd.dd] }\end{array}$ & $\begin{array}{l}\left\langle r_{\mathrm{h}}\right\rangle \\
{[\mathrm{AU}]}\end{array}$ & $\begin{array}{l}\text { Offset } \\
{\left[{ }^{\prime \prime}\right]}\end{array}$ & Lines & $\begin{array}{c}\text { Rotational temperature } \\
\qquad[\mathrm{K}]\end{array}$ & $\begin{array}{c}\text { Gas temperature } \\
{[\mathrm{K}]}\end{array}$ \\
\hline \multicolumn{6}{|c|}{ C/2002 X5 (Kudo-Fujikawa): (2003) } \\
\hline $01 / 13.61$ & 0.553 & 3.5 & $\mathrm{CH}_{3} \mathrm{OH} 157 \mathrm{GHz}$ & $38 \pm 10$ & $30 \pm 10$ \\
\hline $01 / 26.54$ & 0.213 & 3.0 & $\mathrm{CH}_{3} \mathrm{OH} 157 \mathrm{GHz}$ & $320_{-170}^{+\infty}$ & $175_{-90}^{+\infty}$ \\
\hline $01 / 26.54$ & 0.213 & 1.6 & $\mathrm{CH}_{3} \mathrm{CN} 147 \mathrm{GHz}$ & $1500_{-1305}^{+\infty}$ & $>190$ \\
\hline $01 / 26.54$ & 0.213 & 1.0 & $\operatorname{HCNJ}(3-2), v_{2}=1 / v_{2}=0$ & $<245$ & $<530^{1}$ \\
\hline $03 / 12.72$ & 1.184 & 3.0 & $\mathrm{CH}_{3} \mathrm{OH} 157 \mathrm{GHz}$ & $85_{-25}^{+68}$ & $70_{-20}^{+50}$ \\
\hline \multicolumn{6}{|c|}{ C/2002 V1 (NEAT): (2003) } \\
\hline $02 / 17.0$ & 0.120 & 1.9 & $\operatorname{HCNJ}(3-2), v_{2}=1 / v_{2}=0$ & $<285$ & $<574^{1}$ \\
\hline $02 / 17.25$ & 0.116 & 1.6 & $\mathrm{CH}_{3} \mathrm{OH} 252 \mathrm{GHz}$ & $83_{-27}^{+77}$ & $80_{-30}^{+80}$ \\
\hline $02 / 17.3$ & 0.110 & 1.6 & $\mathrm{CH}_{3} \mathrm{OH} 252 \mathrm{GHz}+2 \mathrm{O}_{3} \mathrm{~A}^{+-}$ & $228_{-51}^{+92}$ & $220_{-50}^{+90}$ \\
\hline $02 / 17.6$ & 0.108 & 1.8 & $\mathrm{HCN} J(3-2) /(1-0)$ & $54_{-22}^{+60}$ & $80_{-35}^{+95}$ \\
\hline \multicolumn{6}{|c|}{ C/2006 P1 (McNaught): (2007) } \\
\hline $01 / 16.56$ & 0.228 & 3 & $\mathrm{HCNJ}(3-2) /(1-0)$ & $299_{-204}^{+\infty}$ & $>375^{2}$ \\
\hline $01 / 16.56$ & 0.228 & 5 & $\operatorname{HCNJ}(3-2) /(1-0)$ & $>168^{2}$ & $>600^{2}$ \\
\hline $01 / 16.55$ & 0.229 & 5.9 & $\mathrm{CH}_{3} \mathrm{OH} 157 \mathrm{GHz}$ & $149_{-77}^{+\infty}$ & $110_{-50}^{+\infty}$ \\
\hline $01 / 16.56$ & 0.229 & 4.9 & $\mathrm{CH}_{3} \mathrm{OH} 157 \mathrm{GHz}$ & $88_{-19}^{+32}$ & $70_{-10}^{+20}$ \\
\hline $01 / 17.5$ & 0.255 & 6.5 & $\operatorname{HCNJ}(3-2), v_{2}=1 / v_{2}=0$ & $<278$ & $<677^{1}$ \\
\hline $01 / 17.55$ & 0.255 & 6.7 & $\mathrm{CH}_{3} \mathrm{OH} 157 \mathrm{GHz}$ & $>130$ & $>90$ \\
\hline $01 / 17.55$ & 0.255 & 6.9 & $\mathrm{CH}_{3} \mathrm{CN} 147 \mathrm{GHz}$ & $78_{-28}^{+106}$ & $80_{-30}^{+110}$ \\
\hline
\end{tabular}

Notes. ${ }^{(1)}$ A significant fraction of the molecules are outside the collisional region and a higher gas temperature is needed to populate the $v=1$ level inside the collision zone. ${ }^{(2)}$ A $10 \%$ calibration uncertainty in each line is assumed. 
absorption cross-section $\sigma_{\mathrm{M}}(\lambda)$, in a radiation field $F(\lambda)$ (in photons $\mathrm{m}^{-2} \mathrm{~s}^{-1} \mathrm{~nm}^{-1}$ ) is given by

$\beta_{\mathrm{M}}=\int_{\lambda} \sigma_{\mathrm{M}}(\lambda) F(\lambda) \mathrm{d} \lambda$.

The problem is symmetric around the $z$-axis. At $\left(\rho, z_{r}\right)$, the solar flux at wavelength $\lambda$ will be attenuated to

$F(\lambda, \rho, \phi)=F_{0}(\lambda) \exp [-\tau(\lambda, \rho, \phi)]$

because of the optical thickness along the comet-sun axis. We consider water as the major molecule responsible for the opacity, which is connected to its absorption cross-section $\sigma_{\mathrm{H}_{2} \mathrm{O}}(\lambda)$ by

$\tau(\lambda, \rho, \phi)=\sigma_{\mathrm{H}_{2} \mathrm{O}}(\lambda) \int_{z_{r}}^{\infty} n_{\mathrm{H}_{2} \mathrm{O}}(\rho, z) \mathrm{d} z$

The photons absorbed are mostly those responsible for photodissociation and not fluorescence. Photodissociation of molecules takes place for $\lambda<200 \mathrm{~nm}$ and a significant solar UV field $(\lambda>80 \mathrm{~nm})$. Using the assumptions for the density, we can integrate the density along the $z$-axis to obtain

$$
\begin{aligned}
\int_{z_{r}}^{\infty} n_{\mathrm{H}_{2} \mathrm{O}}(\rho, z) \mathrm{d} z & =\int_{z_{r}=\rho / \tan (\phi)}^{\infty} \frac{Q_{\mathrm{H}_{2} \mathrm{O}}}{4 \pi v_{\exp }\left(\rho^{2}+z^{2}\right)} \mathrm{d} z \\
& =\frac{Q_{\mathrm{H}_{2} \mathrm{O}}}{4 \pi v_{\exp } r} \frac{\phi}{\sin (\phi)} .
\end{aligned}
$$

Hence at any point in the coma, we estimate the opacity

$$
\tau(\lambda, r, \phi)=\langle\tau(\lambda, r)\rangle \frac{4 \phi}{\pi^{2} \sin (\phi)}=C(\lambda) \frac{\phi}{r \sin (\phi)},
$$

where the average value of the opacity over $4 \pi$ steradians at the distance $r$ from the nucleus is

$\langle\tau(\lambda, r)\rangle=C(\lambda) \frac{\pi^{2}}{4} \frac{1}{r}$

with

$C(\lambda)=\frac{\sigma_{\mathrm{H}_{2} \mathrm{O}}(\lambda) Q_{\mathrm{H}_{2} \mathrm{O}}}{4 \pi v_{\exp }}$

The surface corresponding to an opacity $\tau(\lambda, r, \phi)=1.0$ is defined by

$r_{\text {thick }}(\phi)=C(\lambda) \frac{\phi}{\sin (\phi)}=\frac{\sigma_{\mathrm{H}_{2} \mathrm{O}}(\lambda) Q_{\mathrm{H}_{2} \mathrm{O}}}{4 \pi v_{\exp }} \frac{\phi}{\sin (\phi)}$.

According to Eq. (7), the size of the optically thick region tends to infinity in the anti-sunward direction $(\phi=\pi)$. It has a finite length determined by the apparent size of the Sun $\left(2.7^{\circ}\right.$ at $\left.r_{\mathrm{h}}=0.2 \mathrm{AU}\right)$. This region is plotted in Fig. 12 for the three comets, considering only absorption of Lyman $\alpha$ photons by water molecules with a cross-section $\sigma_{\mathrm{H}_{2} \mathrm{O}}(\mathrm{Ly} \alpha)=15 \times 10^{-22} \mathrm{~m}^{2}$ (Lewis et al. 1983).

We next consider HCN photodissociation, but similar equations can be established for other molecules. The effective HCN photodissociation rate at a point $(r, \phi)$ in the coma can then be derived from Eq. (1)

$\beta_{\mathrm{HCN}}(r, \phi)=\int_{\lambda} \sigma_{\mathrm{HCN}}(\lambda) F_{0}(\lambda) \exp \left(-\frac{C(\lambda) \phi}{r \sin (\phi)}\right) \mathrm{d} \lambda$, where $\sigma_{\mathrm{HCN}}(\lambda)$ is the photodissociation cross-section for HCN. The integration can be divided over several wavelength intervals, corresponding to the different absorption bands of $\mathrm{HCN}$ and $\mathrm{H}_{2} \mathrm{O}$

$$
\begin{aligned}
\beta_{\mathrm{HCN}}(r, \phi) & =\sum_{\lambda_{i}} \beta_{\mathrm{HCN}, \lambda_{\mathrm{i}}}(r, \phi) \\
& =\beta_{0, \mathrm{HCN}} \times \sum_{\lambda_{i}} x_{i} \exp \left(-C\left(\lambda_{i}\right) \frac{\phi}{r \sin (\phi)}\right),
\end{aligned}
$$

where $x_{i}$ corresponds to the fraction of the photodissociation rate due to radiation around the wavelength $\lambda_{i}$. For HCN, $88 \%$ of the contribution comes from solar Lyman $\alpha$, i.e., $x_{\text {Ly } \alpha}=0.88$ (Bockelée-Morvan \& Crovisier 1985). To ease computations, we make the approximation

$\sum_{\lambda_{i}} x_{i} \exp \left(-\frac{C\left(\lambda_{i}\right) \phi}{r \sin (\phi)}\right) \approx \exp \left(-\sum_{\lambda_{i}} \frac{x_{i} C\left(\lambda_{i}\right) \phi}{r \sin (\phi)}\right)$.

This rough assumption is valid for small opacities $\left(r>r_{\text {thick }}\right)$ and if the water absorption cross-sections are the same at all wavelengths $\lambda_{i}$. Otherwise, it will slightly overestimate the screening effect in the opaque region. We then define an effective water absorption cross-section for HCN (likewise for the other molecules)

$\left\langle\sigma_{\mathrm{H}_{2} \mathrm{O} \rightarrow \mathrm{HCN}}\right\rangle=\sum_{\lambda_{i}} x_{i} \sigma_{\mathrm{H}_{2} \mathrm{O}}\left(\lambda_{i}\right)=13.8 \times 10^{-22} \mathrm{~m}^{2}$,

where most of the contribution comes from Lyman $\alpha$ $\left(\sigma_{\mathrm{H}_{2} \mathrm{O}}(\right.$ Ly $\alpha)=15 \times 10^{-22} \mathrm{~m}^{2}$, Lee \& Suto 1986; Lewis et al. 1983). This approximation was validated by ourselves for HCN: we estimated numerically that using this mean value for the screening cross-section instead of summing over various wavelength intervals yields only a $\approx 2 \%$ excess error in the estimate of the increase in the number of molecules due to screening.

After solving the differential balance equation for the $\mathrm{HCN}$ density at the distance $r$ from the nucleus in the coma, we find that

$n_{\mathrm{HCN}}(r, \phi)=\frac{Q_{\mathrm{HCN}}}{4 \pi v_{\exp } r^{2}} \exp \left(-\frac{r \beta_{0}}{v_{\mathrm{exp}}} G\left(\frac{r}{C_{\mathrm{HCN}} \frac{\phi}{\sin (\phi)}}\right)\right)$

with

$C_{\mathrm{HCN}}=\frac{\left\langle\sigma_{\mathrm{H}_{2} \mathrm{O} \rightarrow \mathrm{HCN}}\right\rangle Q_{\mathrm{H}_{2} \mathrm{O}}}{4 \pi v_{\exp }}$.

The function $G(x)=\frac{1}{x} \int_{0}^{x} \exp (-1 / t) \mathrm{d} t$ is equal to the exponential integral $G(x)=E_{2}(1 / x)$, which can easily be computed by numerical integration. We note that $G(\infty)=1.0$, so that Eq. (11) gives the classical Haser formula for negligible opacities.

We compared the production rates determined using the density from Eq. (11) to those obtained with the Haser formula. The largest effect is for comet $\mathrm{C} / 2006 \mathrm{P} 1$ with $\mathrm{a} \approx 60 \%$ decrease of the $\mathrm{HCN}$ production rate, and $\approx 40 \%$ decrease for $\mathrm{CH}_{3} \mathrm{OH}$, $\mathrm{CH}_{3} \mathrm{CN}$, or HDO. We did not develop a full 3-D model to take into account phase angles different from $0^{\circ}$ or $180^{\circ}$. But the comparison between the case of a phase angle of $180^{\circ}$, where we can simply use Eq. (11), and replacing Eq. (4) by the averaged value in Eq. (5), only yields a 3\% difference.

Table 7 provides characteristic scalelengths for the three comets and for comparison C/1996 B2 (Hyakutake) and C/1995 


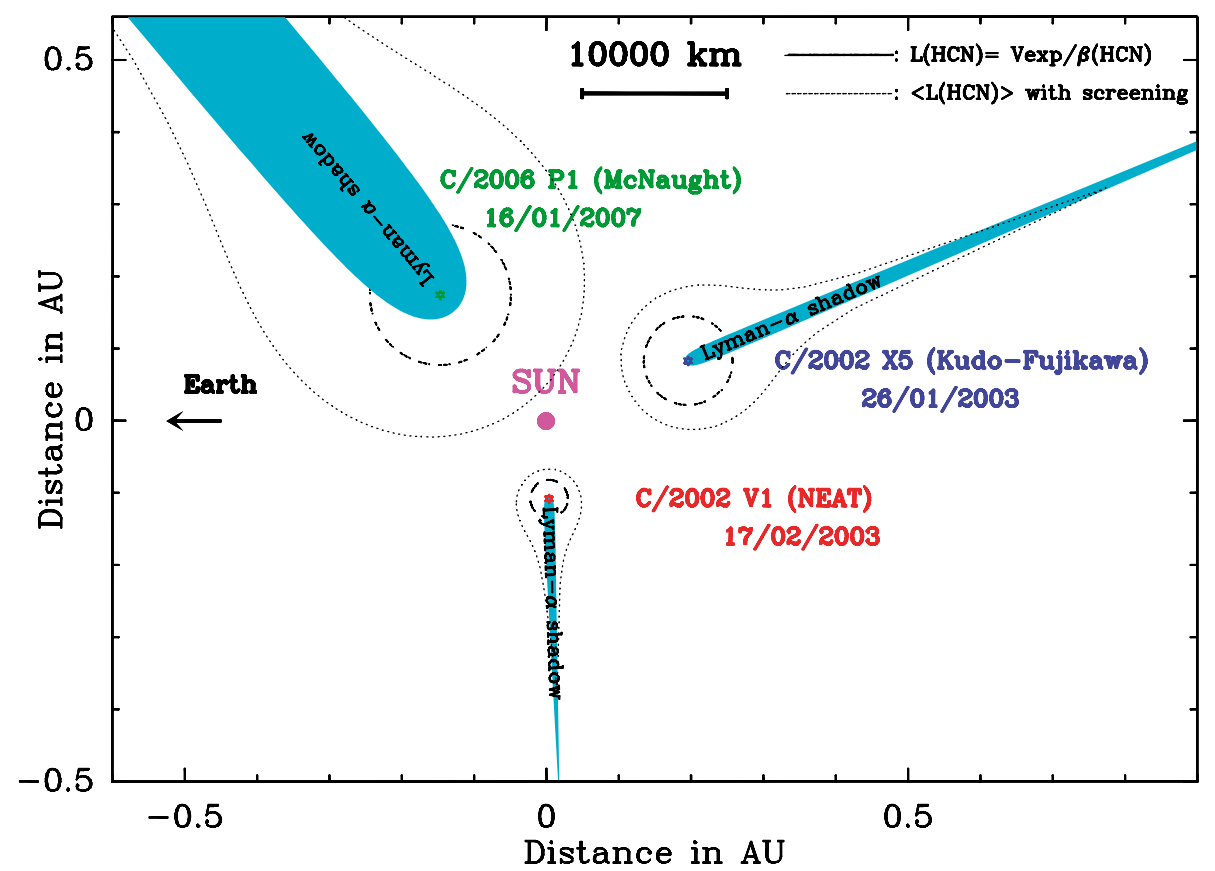

Fig. 12. Sketch of the Earth-Comet-Sun plane, with the positions of each of the three comets at the epoch of the respective observations. In addition (at a different scale given by the $10000 \mathrm{~km}$ bar), three regions in the comae are plotted: in the shaded area, the region opaque to Lyman $\alpha$ (i.e. where opacity at $121.6 \mathrm{~nm}$ towards the Sun is larger than 1.0); in dashed line, the spherical region whose radius corresponds to the Haser scale length of HCN (assuming a constant mean value for the expansion velocity); within the dotted lines, the region where less than $1-1 / e$ of the HCN molecules are photodissociated ( $\approx$ equivalent to its scale length) when the screening is taken into account.
O1 (Hale-Bopp) observed in 1996-1997. In all cases, the optically thick region (at the Lyman $\alpha$ wavelength) is within the water coma $\left(L_{\mathrm{H}_{2} \mathrm{O}}>\left\langle r_{\text {thick }}(\right.\right.$ Ly $\left.\left.\alpha)\right\rangle\right)$ and if one takes into account $\mathrm{OH}$, the assumption of an infinite lifetime for the screening molecules is valid since the coma encompassing $\mathrm{H}_{2} \mathrm{O}$ and $\mathrm{OH}$ is definitely larger than the optically thick region and the $\mathrm{HCN}$ coma. One can also note that for comets C/1996 B2 and $\mathrm{C} / 1995 \mathrm{O} 1, L_{\mathrm{HCN}} \gg\left\langle r_{\text {thick }}(\operatorname{Ly} \alpha)\right\rangle$, so that the screening effect is negligible.

\subsection{Line shapes and gas expansion velocity}

We used the line shapes to estimate the gas expansion velocity following e.g., Biver et al. (1999). Table 9 lists the velocities (VHM) corresponding to the half maximum intensity on both negative and positive sides of the lines. For each comet, we used the most reliably detected lines. To infer the gas velocity from the measured $V H M$, the processes contributing to line broadening should be considered. For the $\mathrm{HCN}(3-2)$ line, we took into account its hyperfine structure (broadening of about $0.03 \mathrm{~km} \mathrm{~s}^{-1}$ and $0.06 \mathrm{~km} \mathrm{~s}^{-1}$, on the negative and positive sides, respectively). Thermal broadening affects the widths of the lines, and depends on the actual gas temperature. When gas expansion velocities are in the range $1-2 \mathrm{~km} \mathrm{~s}^{-1}$, and temperatures are $100-300 \mathrm{~K}$, thermal dispersion essentially smooths the line shape and widens it by less than $0.05 \mathrm{~km} \mathrm{~s}^{-1}$. Optically thick lines, such as $\mathrm{HCN}(3-2)$ in C/2006 P1, are broadened by an additional $0.05 \mathrm{~km} \mathrm{~s}^{-1}$ when the expansion velocity is constant in the coma.

At heliocentric distances $r_{\mathrm{h}}<0.25 \mathrm{AU}$, the photodissociation lifetimes of $\mathrm{HCN}, \mathrm{HNC}, \mathrm{CH}_{3} \mathrm{OH}, \mathrm{CS}, \mathrm{HC}_{3} \mathrm{~N}$, and $\mathrm{H}_{2} \mathrm{CO}$ are shorter than $1 \mathrm{~h}$. In most cases, the beam size $(5000$ to $14000 \mathrm{~km}$ at the comet for C/2002 X5, C/2002 V1, and C/2006 P1 near perihelion) is larger than the molecular scale-length. Therefore, velocity measurements pertain to nucleus distances fixed by the molecular lifetimes and the line widths are mostly representative of the expansion velocity in the coma at a distance equal to the molecular scale-length. Figures 4-10 show that the molecular lines have different widths. The measured "VHMs" velocities are plotted versus the molecular scale-lengths in Figs. 13-16. In the following sections, we constrain the evolution of the gas expansion velocity with distance to nucleus by fitting the measured VHMs, taking into account all sources of line broadening.

\subsubsection{Outgassing pattern and anisotropy}

Lines of C/2002 X5 detected around perihelion, and those of $\mathrm{C} / 2006 \mathrm{P} 1$, show an asymmetric shape, while C/2002 V1 lines are relatively symmetric.

For C/2002 X5, we likely observed a jet or outburst in progress on the night side. All the lines are strongly red-shifted $\left(+0.25 \mathrm{~km} \mathrm{~s}^{-1}\right.$ on average, Table 2) suggesting gas outflow in a preferential direction, independent of acceleration effects. The phase angle was small $\left(26^{\circ}\right.$, Table 1$)$, so the observed asymmetry corresponds to preferential outgassing from the night side. Anisotropy in screening of photodissociation (Sect. 4.2) also contributes to the asymmetry of the lines because lifetimes are longer on the night side. Considering the lines the less affected by screening $\left(\mathrm{HC}_{3} \mathrm{~N}, \mathrm{CH}_{3} \mathrm{OH}\right)$, we found that the outgassing rate is $1.35 \pm 0.1$ times higher on the night side. The mean gas velocity is smaller $\left(0.9\right.$ versus $\left.1.2 \mathrm{~km} \mathrm{~s}^{-1}\right)$ on the dayside of the nucleus. This is most likely owing to shorter molecular lifetimes on the dayside, the measurements sampling thereby molecules closer to the nucleus (Sect. 4.2).

For C/2006 P1, the phase angle was large when the comet was observed (120-140 ${ }^{\circ}$, Fig. 12). The line velocity shifts are slightly negative $\left(-0.05 \mathrm{~km} \mathrm{~s}^{-1}\right.$, Table 4$)$, which could indicate some excess emission from the night side. However, evidence of asymmetric gas acceleration is present. The mean gas velocities inferred from long-lived molecules $\left(\mathrm{HCN}, \mathrm{CH}_{3} \mathrm{OH}\right)$ are 1.7 and $1.3 \mathrm{~km} \mathrm{~s}^{-1}$ on the rear $(\approx$ Sun facing $)$ and front side of the nucleus, respectively, but $\approx 1.2 \mathrm{~km} \mathrm{~s}^{-1}$ on both sides for species with shorter lifetimes (CS and $\mathrm{H}_{2} \mathrm{CO}$ ) (Table 9). The less significant gas acceleration on the night side is likely due to a reduced photolytic heating caused by the screening of water photolysis. The small line blue-shifts suggest that the outgassing rate is barely larger (by a factor of $1.1 \pm 0.1$ ) in the day side, after taking into account screening effects (Sect. 4.2). 
Table 7. Typical scale lengths affected by screening.

\begin{tabular}{lrrrrrrr}
\hline \hline Comet & $\begin{array}{r}\left\langle r_{\mathrm{h}}\right\rangle \\
{[\mathrm{AU}]}\end{array}$ & $\begin{array}{r}Q_{\mathrm{H}_{2} \mathrm{O}} \\
{\left[10^{29} \mathrm{~s}^{-1}\right]}\end{array}$ & $\begin{array}{r}v_{\exp } \\
{\left[\mathrm{km} \mathrm{s}^{-1}\right]}\end{array}$ & $\begin{array}{r}L_{\mathrm{H}_{2} \mathrm{O}} \\
{[\mathrm{km}]}\end{array}$ & $\begin{array}{r}L_{\mathrm{OH}} \\
{[\mathrm{km}]}\end{array}$ & $\begin{array}{r}\left\langle r_{\text {thick }}(\mathrm{Ly} \alpha)\right\rangle \\
{[\mathrm{km}]}\end{array}$ & $\begin{array}{r}L_{\mathrm{HCN}} \\
{[\mathrm{km}]}\end{array}$ \\
\hline C/1996 B2 (Hyakutake) & 0.25 & 5 & 1.60 & 7900 & 14300 & 90 & 6600 \\
C/1995 O1 (Hale-Bopp) & 0.91 & 100 & 1.10 & 70000 & 128000 & 2700 & 58000 \\
C/2002 X5 (Kudo-Fujikawa) & 0.21 & 35 & 1.25 & 3600 & 7200 & 820 & 2900 \\
C/2002 V1 (NEAT) & 0.12 & 20 & 2.00 & 2000 & 3800 & 300 & 1600 \\
C/2006 P1 (McNaught) & 0.23 & 300 & 1.50 & 8100 & 14900 & 5900 & 4900 \\
\hline
\end{tabular}

Notes. $L_{\mathrm{H}_{2} \mathrm{O}}, L_{\mathrm{OH}}, L_{\mathrm{HCN}}$ : unscreened scale lengths of $\mathrm{H}_{2} \mathrm{O}, \mathrm{OH}$, and $\mathrm{HCN}$, taking into account solar activity, expansion velocity, and heliocentric distance. $\left\langle r_{\text {thick }}(\operatorname{Ly} \alpha)\right\rangle$ : mean radius of the optically thick Lyman $\alpha$ envelope $\left(\frac{\pi^{2}}{4} C(\operatorname{Ly} \alpha)\right)$.

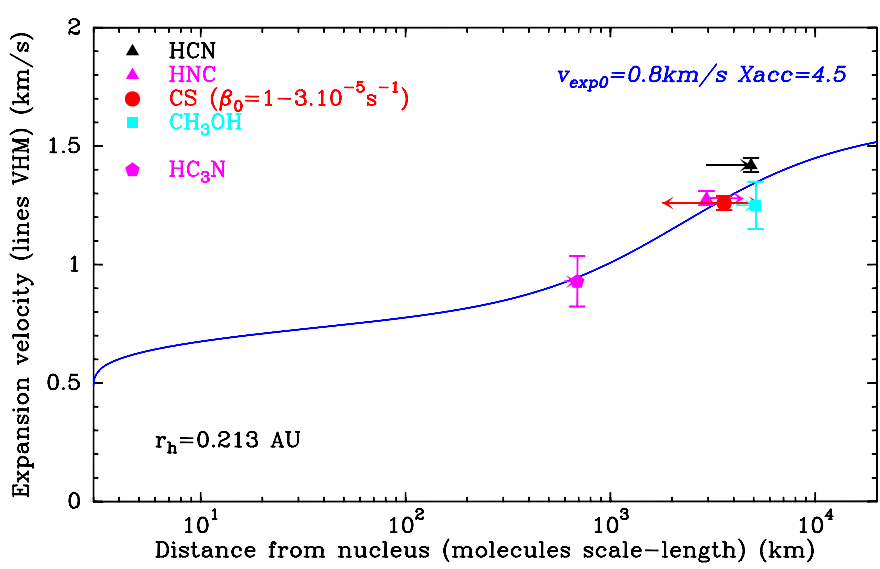

Fig. 13. The evolution of the expansion velocity with distance to the nucleus in the coma of comet C/2002 X5 (Kudo-Fujikawa) on 26.5 January 2003. The measured lines widths have been plotted with their errorbars at a distance corresponding to the molecular lifetime. Arrows represent the effect on scalelength of the $\beta_{0}=1-3 \times 10^{-5} \mathrm{~s}^{-1}$ (Table 9) domain for $\mathrm{CS}$. For $\mathrm{HCN}, \mathrm{HNC}$, and $\mathrm{CH}_{3} \mathrm{OH}$, the arrow points to the increase in scalelength due to the screening.

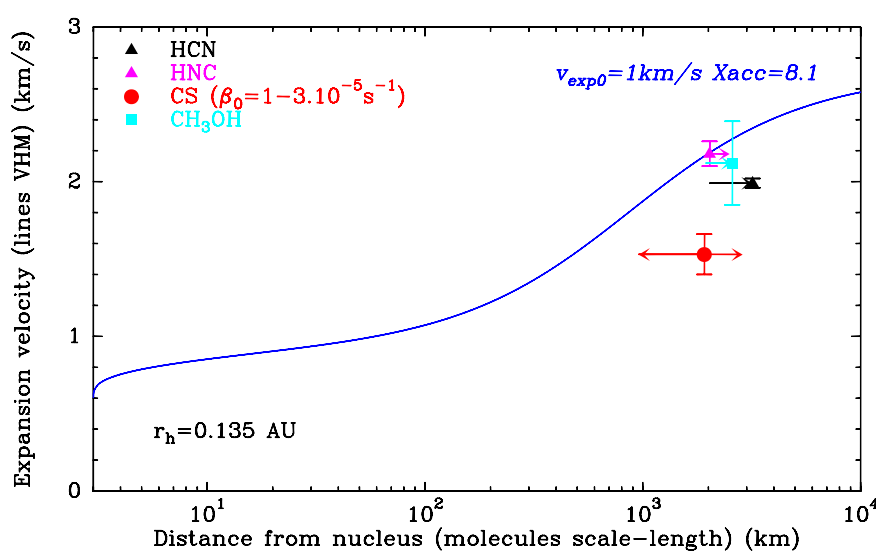

Fig. 14. The evolution of the expansion velocity with distance to the nucleus in the coma of comet C/2002 V1 (NEAT) on 16.5 February 2003. Measurements of line widths from Table 9 are plotted as in Fig. 13.

In the case of $\mathrm{C} / 2002 \mathrm{~V} 1$, the phase angle was close to $90^{\circ}$ (Table 1), so that the line shapes are unaffected by day/night asymmetries.

\subsubsection{Expansion velocity acceleration}

Since there is evidence of gas acceleration in the coma, we used a variable expansion velocity in the coma $v_{\exp }(r)$, which

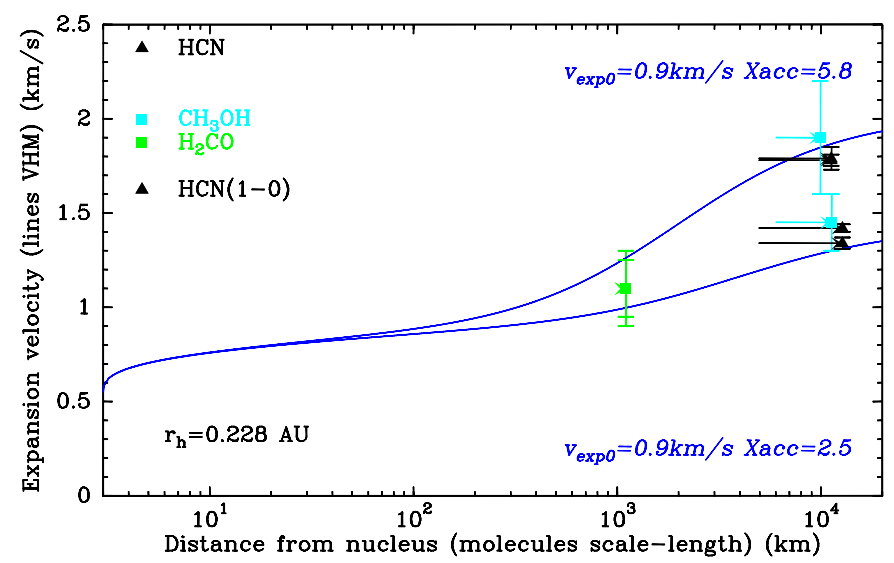

Fig. 15. The evolution of the expansion velocity with distance to the nucleus in the coma of comet C/2006 P1 (McNaught) on 16.5 January 2007. Measurements of line widths from Table 9 are plotted as in Fig. 13. The upper values $\left(v_{\exp }(r)\right.$ and $\left.V H M\right)$ correspond to the $\sim$ dayside larger velocities $(v>0)$.

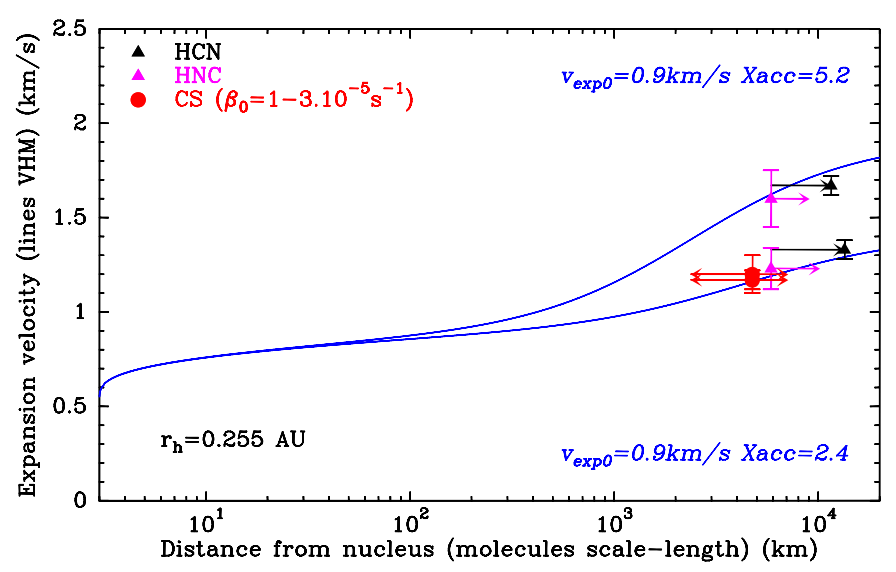

Fig. 16. The evolution of the expansion velocity with distance to the nucleus in the coma of comet C/2006 P1 (McNaught) on 17.5 January 2007. Scales as in Fig. 15 with upper values for dayside data.

is plotted in Figs. 13-16. This function reproduces the general shape of gas-dynamic simulations (Combi \& Smyth 1988). The parameter $v_{\exp }(r)^{2}$ is adjusted to match the observed line widths (Table 9) when computing line shapes. These velocity

\footnotetext{
${ }^{2} v_{\exp }(r)=v_{\exp 0} \times[0.6+0.3 \sqrt[3]{\log (r / 3)}]+v_{\exp 0} \times$

$\left[0.1 x_{\text {acc }}\left(1+\tanh \left(1.3 \log \left(\frac{r\left(1+x_{\text {acc }}\right)}{60000 r_{\mathrm{h}}}\right)\right)\right)\right]$, with $r$ in $\mathrm{km}$.
} 
plots provide the two free parameters used to compute $v_{\text {exp }}(r)$ and lead to the following comments:

1. $\mathrm{C} / 2002 \mathrm{X} 5$ at $r_{\mathrm{h}}=0.21 \mathrm{AU}$ (Fig. 13): positive and negative sides $V H M$ s were both fitted using the same function. The computed line shapes for $\mathrm{HC}_{3} \mathrm{~N}(28-27), \mathrm{CH}_{3} \mathrm{OH}\left(5_{0}-5_{-1}+\right.$ $\left.6_{0}-6_{-1}+7_{0}-7_{-1}\right) \mathrm{E}$, and $\mathrm{HCN}(3-2)$, taking into account screening and a night/day outgassing rate ratio of 1.35 , have exactly the measured width within the errorbars. Doppler shifts of the lines $\left(+0.095,+0.172,+0.243 \mathrm{~km} \mathrm{~s}^{-1}\right.$, predicted, respectively) are also in good agreement.

2. C/2002 V1 (Fig. 14): asymmetry in the lines (due to day/night outgassing asymmetry and screening effect) is neither seen nor expected because of the phase angle. We have thus averaged the VHM measurements on both sides of the lines. However, the two days of observations require two different velocity profiles, with stronger acceleration on the second day closer to the Sun. For this comet, we did not observe short-lived species (e.g., $\mathrm{HC}_{3} \mathrm{~N}, \mathrm{H}_{2} \mathrm{CO}$, or $\mathrm{H}_{2} \mathrm{~S}$ ), so the velocity profile is poorly constrained close to the nucleus. The CS line widths suggest that the CS lifetime is significantly shorter than the HCN lifetime.

3. C/2006 P1: data were divided into four subsets: positive and negative velocity sides of the lines on the 16th (Fig. 15) and 17th of January 2007 (Fig. 16). The species with the smaller scale length $\left(\mathrm{H}_{2} \mathrm{CO}\right)$ was not observed on $17 \mathrm{Jan}$. but we assumed a similar acceleration in the coma for both days, scaled to the HCN lines VHMs. A stronger acceleration is present for molecules moving in an opposite direction to the observer $(v>0)$, which is consistent with stronger acceleration towards the dayside (Fig. 12: phase angle of $120-140^{\circ} \ll 90^{\circ}$ ).

\subsection{Constraints on CS and HNC lifetimes}

We assume that $\mathrm{CS}$ is the photodissociation product of $\mathrm{CS}_{2}$. It forms very close to the nucleus since $\mathrm{CS}_{2}$ photodissociates into $\mathrm{CS}$ in less than $30 \mathrm{~s}$ at $r_{\mathrm{h}}<0.25 \mathrm{AU}$. We assume that there is no additional excitation effect to those not modeled in Biver et al. (1999) that would strongly affect its rotational population mimicking photodissociation. Hence, the width of CS lines (clearly narrower than HCN lines; Figs. 4, 6, 10, and Table 9) can be converted into a scale-length estimate using line-shape modeling with $v_{\exp }(r)$. The scale-length of CS is determined by the gas expansion velocity, its photodissociation rate, and the screening effects. Since the photodissociation process of CS is unknown, we investigated $\beta_{0, \mathrm{CS}}=1-3 \times 10^{-5} \mathrm{~s}^{-1}$ for the photodissociation rate at $1 \mathrm{AU}$ and $\sigma_{\mathrm{H}_{2} \mathrm{O} \rightarrow \mathrm{CS}}=0-12 \times 10^{-22} \mathrm{~m}^{2}$ (i.e. values smaller than or comparable to $\mathrm{HCN}$ for the screening cross-section). Table 8 summarizes the findings. There is no unique solution, but grouping measurements comet by comet, the closer matches are found for $\left(\beta_{0, \mathrm{CS}} \geq 1.7 \times 10^{-5} \mathrm{~s}^{-1}, \sigma_{\mathrm{H}_{2} \mathrm{O} \rightarrow \mathrm{CS}} \geq 6 \times 10^{-22} \mathrm{~m}^{2}\right)$, $\left(\beta_{0, \mathrm{CS}}=2.9 \pm 0.7 \times 10^{-5} \mathrm{~s}^{-1}\right.$, for $\left.\sigma_{\mathrm{H}_{2} \mathrm{O} \rightarrow \mathrm{CS}}=6 \times 10^{-22} \mathrm{~m}^{2}\right)$, and $\left(\beta_{0, \mathrm{CS}}=4.3 \pm 1.2 \times 10^{-5} \mathrm{~s}^{-1}, \sigma_{\mathrm{H}_{2} \mathrm{O} \rightarrow \mathrm{CS}} \geq 6 \times 10^{-22} \mathrm{~m}^{2}\right)$ for $\mathrm{C} / 2002 \mathrm{X} 5, \mathrm{C} / 2002 \mathrm{~V} 1$, and C/2006 P1, respectively. The screening of photodissociation is necessary to achieve closer agreement between the night- and dayside measurements. In addition, the detection of CS at only $0.1 \mathrm{AU}$ from the Sun in $\mathrm{C} / 2002 \mathrm{~V} 1$ requires a lifetime $\left(\beta_{0, \mathrm{CS}} \ll 4 \times 10^{-5} \mathrm{~s}^{-1}\right)$ long enough to get realistic abundances $\left(\mathrm{CS} / \mathrm{H}_{2} \mathrm{O} \ll 1 \%\right.$, this ratio being $<0.2 \%$ at $1 \mathrm{AU}$ in all comets where it has been measured). Values $\beta_{0, \mathrm{CS}}=2.5 \pm 0.5 \times 10^{-5} \mathrm{~s}^{-1}$ and $\sigma_{\mathrm{H}_{2} \mathrm{O} \rightarrow \mathrm{CS}}=6 \times 10^{-22} \mathrm{~m}^{2}$ are consistent with all measurements and are used to determine the production rates.
Table 8. Constraints on the CS photodissociation rate at $1 \mathrm{AU}\left(\beta_{0 \mathrm{CS}}\right)$.

\begin{tabular}{lccc}
\hline \hline$\left\langle r_{\mathrm{h}}\right\rangle$ & $\beta_{0 \mathrm{CS}}$ & $\begin{array}{c}\sigma_{\mathrm{H}_{2} \mathrm{O} \rightarrow \mathrm{CS}} \\
{\left[\mathrm{m}^{2}\right]}\end{array}$ & $\begin{array}{c}\text { Lifetime }^{1} \\
\text { at } 1 \mathrm{AU}[\mathrm{s}]\end{array}$ \\
\hline $\mathrm{AU}]$ & {$\left[\mathrm{s}^{-1}\right]$} & & \\
$\mathrm{C} / 2002 \mathrm{X} 5: V H M>0$ & & \\
0.213 & $0.65 \pm 0.15 \times 10^{-5}$ & no screening & 154000 \\
0.213 & $1.1 \pm 0.3 \times 10^{-5}$ & $3 \times 10^{22}$ & 108100 \\
0.213 & $1.25 \pm 0.35 \times 10^{-5}$ & $6 \times 10^{22}$ & 107500 \\
0.213 & $1.4 \pm 0.3 \times 10^{-5}$ & $9 \times 10^{22}$ & 106900 \\
0.213 & $1.6 \pm 0.3 \times 10^{-5}$ & $12 \times 10^{22}$ & 104300 \\
\hline $\mathrm{C} / 2002 \mathrm{X} 5: V H M<0$ & & \\
0.213 & $2.7 \pm 0.7 \times 10^{-5}$ & no screening & 37000 \\
0.213 & $2.3 \pm 0.7 \times 10^{-5}$ & $3 \times 10^{22}$ & 49400 \\
0.213 & $2.2 \pm 0.7 \times 10^{-5}$ & $6 \times 10^{22}$ & 55300 \\
0.213 & $2.1 \pm 0.7 \times 10^{-5}$ & $9 \times 10^{22}$ & 61000 \\
0.213 & $2.0 \pm 0.7 \times 10^{-5}$ & $12 \times 10^{22}$ & 66600 \\
\hline $\mathrm{C} / 2002 \mathrm{~V} 1: 16.6 \mathrm{Jan} .2003$ & & \\
0.136 & $2.8 \pm 1.0 \times 10^{-5}$ & no screening & 36000 \\
0.136 & $3.2 \pm 1.2 \times 10^{-5}$ & $3 \times 10^{22}$ & 40400 \\
0.136 & $3.8 \pm 1.6 \times 10^{-5}$ & $6 \times 10^{22}$ & 40800 \\
\hline $\mathrm{C} / 2002 \mathrm{~V} 1: 17.5 \mathrm{Jan} .2003$ & & \\
0.108 & $2.05 \pm 0.45 \times 10^{-5}$ & no screening & 49000 \\
0.108 & $2.45 \pm 0.6 \times 10^{-5}$ & $3 \times 10^{22}$ & 56400 \\
0.108 & $2.95 \pm 0.75 \times 10^{-5}$ & $6 \times 10^{22}$ & 57700 \\
\hline $\mathrm{C} / 2006 \mathrm{P} 1: V H M<0$ & & \\
0.255 & $0.95 \pm 0.4 \times 10^{-5}$ & no screening & 105000 \\
0.255 & $2.05 \pm 1.1 \times 10^{-5}$ & $3 \times 10^{22}$ & 77000 \\
0.255 & $3.2 \pm 2.0 \times 10^{-5}$ & $6 \times 10^{22}$ & 71000 \\
\hline $\mathrm{C} / 2006 \mathrm{P} 1: V H M>0$ & & \\
0.255 & $4.3 \pm 2.1 \times 10^{-5}$ & no screening & 23000 \\
0.255 & $5.1 \pm 2.4 \times 10^{-5}$ & $3 \times 10^{22}$ & 36000 \\
0.255 & $6.4 \pm 3.4 \times 10^{-5}$ & $6 \times 10^{22}$ & 34000 \\
\hline
\end{tabular}

Notes. ${ }^{(1)}$ Determined from the ratio of the total number of molecules in the coma divided by the production rate, scaled as $1 / r_{\mathrm{h}}^{2}$ to $1 \mathrm{AU}$.

For HNC, we assume similar spectroscopic properties (e.g. UV absorption spectrum) to those of HCN. Slight differences in line shapes may underline differences. In C/2002 X5 and $\mathrm{C} / 2006 \mathrm{P} 1$, the $\mathrm{HNC}(3-2)$ line is slightly narrower than $\mathrm{HCN}(3-2)$ suggesting stronger photodissociation, weaker screening, and/or other destruction processes in the coma. But this effect is not observed in C/2002 V1. A possible interpretation is that HNC is partly created in the coma by chemical reactions, as suggested by Rodgers \& Charnley (1998). This would partly compensate for the shortening of its scale-length. A parent scale-length of $\approx 1300 \mathrm{~km}$ at $r_{\mathrm{h}}=0.2 \mathrm{AU}, \beta_{0, \mathrm{HNC}} \approx 1.3 \times \beta_{0, \mathrm{HCN}}$, and $\sigma_{\mathrm{H}_{2} \mathrm{O} \rightarrow \mathrm{HNC}} \approx 0.9 \times \sigma_{\mathrm{H}_{2} \mathrm{O} \rightarrow \mathrm{HCN}}$ would provide the closest agreements between model and data, but the constraints are not strong enough to infer a definite conclusion.

\section{Production rates and abundances}

The production rates were computed using models that incorporate collisions with neutrals and electrons, and radiative pumping by the solar radiation (Biver et al. 1999, 2000, 2006a). We did not consider infra-red pumping by the large and warm dust coma. Assuming a dust-to-gas ratio of 1.0 (which might be underestimated for the dustier comets C/2006 P1 and C/2002 V1), and the simplified approach by Crovisier \& Encrenaz (1983), we estimate that for $\mathrm{HCN}$ or $\mathrm{CH}_{3} \mathrm{OH}$ in comet $\mathrm{C} / 2006 \mathrm{P} 1$ (McNaught), the vibrational pumping by the dust infrared radiation is stronger than that by the solar radiation field within $2000-7000 \mathrm{~km}$ of the nucleus. However, collisions with water 
Table 9. Line widths and photodissociation rates.

\begin{tabular}{|c|c|c|c|c|c|c|c|c|c|}
\hline \multirow{2}{*}{$\begin{array}{c}\text { UT date } \\
{[\mathrm{mm} / \mathrm{dd} . \mathrm{dd}]}\end{array}$} & \multirow{2}{*}{$\begin{array}{l}\left\langle r_{\mathrm{h}}\right\rangle \\
{[\mathrm{AU}]}\end{array}$} & \multirow[t]{2}{*}{ Line } & \multicolumn{2}{|c|}{ Beam size } & \multicolumn{2}{|c|}{ VHM } & \multirow{2}{*}{$\begin{array}{c}v_{\exp } \\
{\left[\mathrm{km} \mathrm{s}^{-1}\right]}\end{array}$} & \multirow{2}{*}{$\begin{array}{c}\beta_{0} \\
{\left[\mathrm{~s}^{-1}\right]}\end{array}$} & \multirow{2}{*}{$\begin{array}{c}L_{\mathrm{d}} \\
{[\mathrm{km}]}\end{array}$} \\
\hline & & & {$\left[{ }^{\prime \prime}\right]$} & {$[\mathrm{km}]$} & {$\left[\mathrm{km} \mathrm{s}^{-1}\right]$} & {$\left[\mathrm{km} \mathrm{s}^{-1}\right]$} & & & \\
\hline \multicolumn{10}{|c|}{ C/2002 X5: (2003) } \\
\hline $01 / 13.60$ & 0.553 & $\operatorname{HCN}(3-2)^{1}$ & 9.6 & 7190 & $-1.09 \pm 0.07$ & $+1.20 \pm 0.07$ & 0.90 & $1.7 \times 10^{-5}$ & 14330 \\
\hline $01 / 26.54$ & 0.213 & $\mathrm{HCN}(3-2)$ & 9.4 & 7990 & $-0.97 \pm 0.03$ & $+1.42 \pm 0.02$ & 1.25 & $1.92 \times 10^{-5}$ & $2950-4870^{2}$ \\
\hline $01 / 26.54$ & 0.213 & $\mathrm{HNC}(3-2)$ & 9.2 & 7820 & $-0.86 \pm 0.11$ & $+1.28 \pm 0.03$ & 1.25 & $1.92 \times 10^{-5}$ & $2950-4500^{2}$ \\
\hline $01 / 26.56$ & 0.212 & $\operatorname{CS}(3-2)$ & 17.5 & 14880 & $-0.92 \pm 0.06$ & $+1.26 \pm 0.03$ & 1.20 & $1-3 \times 10^{-5}$ & $1800-5400$ \\
\hline $01 / 26.60$ & 0.212 & $\mathrm{HC}_{3} \mathrm{~N}(28-27)$ & 9.7 & 8250 & $-0.73 \pm 0.18$ & $+0.93 \pm 0.11$ & 0.90 & $6.8 \times 10^{-5}$ & $690^{2}$ \\
\hline \multirow[t]{2}{*}{$01 / 26.55$} & 0.213 & \multicolumn{8}{|c|}{$\mathrm{CH}_{3} \mathrm{OH}\left(\left(5_{0}-5_{-1}\right)+\left(6_{0}-6_{-1}\right)+\left(7_{0}-7_{-1}\right) \mathrm{E}\right)$} \\
\hline & & & 15.5 & 13170 & $-0.92 \pm 0.20$ & $+1.25 \pm 0.10$ & 1.25 & $1.43 \times 10^{-5}$ & $4120-5130^{2}$ \\
\hline $03 / 12.72$ & 1.184 & $\mathrm{HCN}(3-2)$ & 9.6 & 7630 & $-0.65 \pm 0.04$ & $+0.52 \pm 0$ & 0.65 & $1.6 \times 10^{-5}$ & 47460 \\
\hline \multicolumn{10}{|c|}{ C/2002 V1: (2003) } \\
\hline $02 / 16.55$ & 0.136 & $\mathrm{HCN}(3-2)$ & 9.3 & 6600 & $-2.07 \pm 0.06$ & $+2.26 \pm 0.04$ & 2.00 & $1.8 \times 10^{-5}$ & $2080-2950^{2}$ \\
\hline $02 / 16.57$ & 0.135 & $\mathrm{HNC}(3-2)$ & 9.2 & 6520 & $-2.34 \pm 0.22$ & $+2.13 \pm 0.26$ & 2.00 & $1.8 \times 10^{-5}$ & $2030-2500^{2}$ \\
\hline $02 / 16.55$ & 0.136 & $\mathrm{CS}(3-2)$ & 17.3 & 12270 & $-1.60 \pm 0.35$ & $+1.65 \pm 0.18$ & 1.60 & $1-3 \times 10^{-5}$ & $1000-3000$ \\
\hline $02 / 17.10$ & 0.120 & \multicolumn{8}{|c|}{$\mathrm{CH}_{3} \mathrm{OH}\left(\left(7_{3}-7_{2}\right) \mathrm{A}^{+-}+\left(6_{3}-6_{2}\right) \mathrm{A}^{+-}+\left(5_{3}-5_{2}\right) \mathrm{A}^{+-}+\left(4_{3}-4_{2}\right) \mathrm{A}^{+-}+\left(7_{3}-7_{2}\right) \mathrm{A}^{-+}\right)$} \\
\hline & & & 10.0 & 7120 & $-1.96 \pm 0.34$ & $+2.37 \pm 0.43$ & 2.00 & $1.38 \times 10^{-5}$ & $2090-2580^{2}$ \\
\hline $02 / 17.50$ & 0.108 & $\mathrm{HCN}(3-2)$ & 9.3 & 6650 & $-2.07 \pm 0.07$ & $+2.24 \pm 0.06$ & 2.0 & $1.8 \times 10^{-5}$ & $1300-2250^{2}$ \\
\hline $02 / 17.50$ & 0.108 & $\mathrm{CS}(3$ & 17.3 & 12370 & $-2.60 \pm 0.60$ & $+1.65 \pm 0.10$ & 1.6 & $1-3 \times 10^{-5}$ & $620-1870$ \\
\hline $02 / 17.60$ & 0.105 & $\mathrm{HCN}(1-0)$ & 26.8 & 19180 & $-1.3 \pm 1.1$ & $+2.9 \pm 1.1$ & 2.00 & $1.8 \times 10^{-5}$ & $1230-2200^{2}$ \\
\hline \multicolumn{10}{|c|}{ C/2006 P1: (2007) } \\
\hline $01 / 16.56$ & 0.228 & $\mathrm{HCN}(3-2)$ & 9.3 & 5540 & $-1.42 \pm 0.02$ & $+1.78 \pm 0.03$ & 1.50 & $1.60 \times 10^{-5}$ & $4870-12300^{2}$ \\
\hline $01 / 16.56$ & 0.228 & $\mathrm{HCN}(1-0)$ & 26.5 & 15780 & $-1.34 \pm 0.03$ & $+1.79 \pm 0.06$ & 1.50 & $1.60 \times 10^{-5}$ & $4870-12300^{2}$ \\
\hline $01 / 16.55$ & 0.228 & $\mathrm{H}_{2} \mathrm{CO}\left(3_{12}-2_{11}\right)$ & 10.8 & 6430 & $-1.10 \pm 0.20$ & $+1.10 \pm 0.15$ & 1.1 & $2.0 \times 10^{-4}$ & $290^{3} \rightarrow 1210$ \\
\hline $01 / 16.56$ & 0.228 & \multicolumn{8}{|c|}{$\mathrm{CH}_{3} \mathrm{OH}\left(\left(4_{0}-4_{-1}\right)+\left(5_{0}-5_{-1}\right)+\left(6_{0}-6_{-1}\right)+\left(7_{0}-7_{-1}\right) \mathrm{E}\right)$} \\
\hline & & & 15.5 & 9230 & $-1.45 \pm 0.15$ & $+1.90 \pm 0.30$ & 1.50 & $1.32 \times 10^{-5}$ & $5900-10600^{2}$ \\
\hline $01 / 17.56$ & 0.255 & $\mathrm{HCN}(3-2)$ & 9.3 & 5620 & $-1.33 \pm 0.05$ & $+1.67 \pm 0.05$ & 1.45 & $1.60 \times 10^{-5}$ & $5890-12000^{2}$ \\
\hline $01 / 17.55$ & 0.255 & $\mathrm{HNC}(3-2)$ & 9.2 & 5480 & $-1.23 \pm 0.11$ & $+1.60 \pm 0.15$ & 1.40 & $1.60 \times 10^{-5}$ & $5670-10500^{2}$ \\
\hline $01 / 17.56$ & 0.255 & $\mathrm{CS}(3-2)$ & 17.0 & 10270 & $-1.17 \pm 0.05$ & $+1.20 \pm 0.10$ & 1.2 & $1-3 \times 10^{-5}$ & 2620-9800 \\
\hline $01 / 17.59$ & 0.256 & $\mathrm{HCO}+(1-0)$ & 26.2 & 15830 & $-2.80 \pm 0.53$ & $+2.03 \pm 0.53$ & - & & \\
\hline
\end{tabular}

Notes. ${ }^{(1)}$ Only low resolution $\left(1 \mathrm{MHz}=1.2 \mathrm{~km} \mathrm{~s}^{-1}\right)$ spectra. ${ }^{(2)}$ Scale-length taking into account screening (Sect. 4.2): based on the equivalent lifetime that would lead to the same number of molecule in the coma without screening. ${ }^{(3)}$ When we assume that $\mathrm{H}_{2} \mathrm{CO}$ comes from an extended source with scale-length $1.75 \times L_{\mathrm{H}_{2} \mathrm{CO}}$, this value increases by a factor $\approx 4.23$ (to get a $1 / e$ decrease from the peak value at $1.30 \times L_{\mathrm{H}_{2} \mathrm{CO}}$ ).

still dominate in a region twice as large and control the excitation of the rotational levels.

We used the radial profiles of the gas expansion velocity determined in the previous section. In some cases, we considered different velocity profiles to interpret the positive and negative sides of the lines, but similar production rates were obtained as long as the velocity profiles provided a good fit to the line widths. To compute rotational level populations and collision rates with neutrals, we used the gas temperatures given in Sect. 4.1. Inferred production rates are given in Table 10. As discussed in the next section, they are possibly wrong by a factor 1.5 , because of uncertainties in the model parameters.

\subsection{Uncertainties due to model parameters}

The photodissociative lifetimes were taken from Crovisier (1994), except for CS and HNC, which we constrained from the present observations (Sect. 4.4). We took into account solar activity when computing the photodissociation rates (Crovisier 1989, 1994; Bockelée-Morvan \& Crovisier 1985). The uncertainty introduced by our simplifying assumptions in the modeling of photolysis screening is not very large $(<15 \%$, not considering water production rate uncertainties). Derived $\mathrm{HCN}$ production rates are a factor between 1.4 and 2.5 smaller than when this effect is omitted.

The main source of error in the computation of production rates is the uncertainty in the gas kinetic temperature (except for $\mathrm{C} / 2002 \mathrm{X} 5$ at $r_{\mathrm{h}}>0.5 \mathrm{AU}$, where the temperature is well constrained). We assumed constant coma temperatures of 180 , 150 , and $300 \mathrm{~K}$ for near perihelion data of comets $\mathrm{C} / 2002 \mathrm{X} 5$, C/2002 V1, and C/2006 P1, respectively (Sect. 4.1). An increase (respectively decrease) in these values by $50 \%$ affects the production rate determinations in the following way:

- $Q_{\mathrm{HCN}}$ and $Q_{\mathrm{HNC}}$ are increased by +33 to $+40 \%(\mathrm{C} / 2006 \mathrm{P} 1)$ (respectively, decreased by $31 \%$ to $39 \%$ );

- the same trend is observed for $Q_{\mathrm{CS}}$ and $Q_{\mathrm{CH}_{3} \mathrm{CN}}: \pm 45 \%$ for a $\pm 50 \%$ variation in the gas temperature;

- $Q_{\mathrm{CH}_{3} \mathrm{OH}}$ is still more sensitive to the assumed temperature, because of excitation of the torsional band at high $T: \mathrm{a} \pm 50 \%$ change in temperature causes changes of $+51 /-39 \%,+72 /-$ $53 \%$, and $+102 /-64 \%$ in the production rates for $\mathrm{C} / 2002 \mathrm{~V} 1$, $\mathrm{C} / 2002 \mathrm{X} 5$, and C/2006 P1, respectively;

- $Q_{\mathrm{HC}_{3} \mathrm{~N}}$ is minimal for $T \approx 200 \mathrm{~K}$. The retrieved $Q_{\mathrm{HC}_{3} \mathrm{~N}}$ is $50 \%$ higher when either increasing or decreasing the nominal temperature $(180 \mathrm{~K})$ by $50 \%$.

Therefore, most abundances relative to $\mathrm{HCN}$ are not significantly sensitive to the assumed $T$. Two exceptions are the $\mathrm{CH}_{3} \mathrm{OH} / \mathrm{HCN}\left(+20\right.$ to $+40 \%$ for $\Delta T=+50 \%$ ) and $\mathrm{HC}_{3} \mathrm{~N} / \mathrm{HCN}$ $(+100 \%$ for $\Delta T=+50 \%)$ ratios.

\subsection{Short- and long-term variations in the production rates}

The most significant time variations are observed for C/2002 X5. Rapid variations are observed around perihelion (Fig. 17). Strong variations in the light curve and water production rate are 


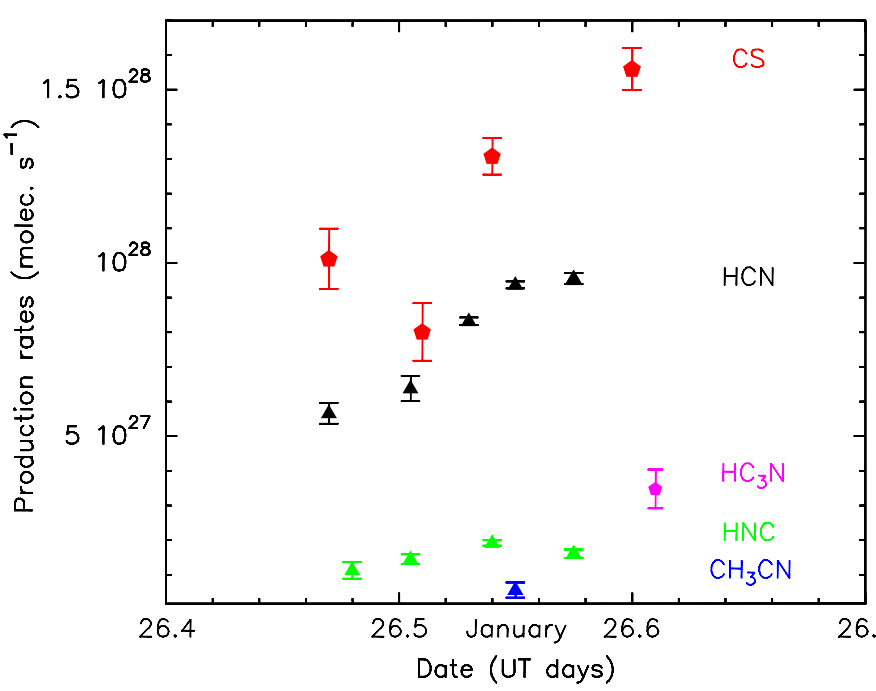

Fig. 17. Molecular production rates in comet C/2002 X5 (KudoFujikawa) as a function of time on 26 January 2003: this plot shows the rapid increase over $\approx 3 \mathrm{~h}$ of observations for $\mathrm{HCN}, \mathrm{CS}$, and $\mathrm{HNC}$. The values for $\mathrm{CH}_{3} \mathrm{OH}$ and $\mathrm{CH}_{3} \mathrm{CN}$ are the averages over the full period.

also reported by Bout et al. (2003) and Povich et al. (2003). On 26.5 January 2003, the production rates of HCN, CS and HNC increased by $\approx 70 \%$ over a time interval of $\approx 0.11$ days (Table 10 , Fig. 17).

Over the 2-3 days of observations of comets C/2002 V1 and C/2006 P1, production rates also varied. For C/2002 V1, an heliocentric dependence $Q_{\mathrm{CS}} \propto r_{\mathrm{h}}^{-0.8}$ to $r_{\mathrm{h}}^{-1.5}$ is observed, while for C/2006 P1 $Q_{\mathrm{HCN}} \propto r_{\mathrm{h}}^{-4.5}$. For C/2006 P1, the variation in the $\mathrm{HCN}$ production rate is steeper than the variation in the $\mathrm{H}_{2} \mathrm{O}$ production rate $\left(2.4 \times 10^{29} r_{\mathrm{h}}^{-3}\right.$ molec. $\left.\mathrm{s}^{-1}\right)$ deduced from the $\mathrm{OH}$ observations (Table 5). This inconsistency could be due to rotationinduced time variations and the flux loss cause by anomalous refraction on 17 January being unable to be quantified.

The long-term (over 2 months) evolution of the production rates of $\mathrm{C} / 2002 \mathrm{X} 5$ is shown in Fig. 18. The $\mathrm{HCN}, \mathrm{HNC}$, and $\mathrm{CH}_{3} \mathrm{OH}$ production rates vary according to $Q \propto r_{\mathrm{h}}^{-3.5 \pm 0.5}$, pre and post-perihelion, as for $\mathrm{H}_{2} \mathrm{O}$ post-perihelion $((2.6 \pm 0.2) \times$ $10^{28} r_{\mathrm{h}}^{-3.5 \pm 0.2}$ molec. $\mathrm{s}^{-1}$ ).

\subsection{Molecular abundances and discussion}

Table 11 summarizes the molecular abundances relative to water and $\mathrm{HCN}$ in the three comets.

The water production rates used as reference for the short heliocentric distances $\left(r_{\mathrm{h}}<0.3 \mathrm{AU}\right)$ are uncertain, as discussed in Sect. 3. For C/2002 X5, according to the short-term variations seen for all molecules, we assumed $Q_{\mathrm{H}_{2} \mathrm{O}}=35+$ $10 \times \sin \left(2 \pi \frac{t[d]-26.54}{0.2}\right) \times 10^{29}$ molec. $\mathrm{s}^{-1}$. For C/2006 P1, we used $Q_{\mathrm{H}_{2} \mathrm{O}}=2.4 \times 10^{29} r_{\mathrm{h}}^{-3}$ molec. $\mathrm{s}^{-1}$, and for $\mathrm{C} / 2002 \mathrm{~V} 1$ $Q_{\mathrm{H}_{2} \mathrm{O}}=2.7 \times 10^{29} r_{\mathrm{h}}^{-1}$ molec. $\mathrm{s}^{-1}$, these values being possibly in error by $\pm 50 \%$. Resulting abundances relative to water are roughly in agreement with abundances measured in other comets (Biver et al. 2002a). The $\mathrm{CH}_{3} \mathrm{OH} / \mathrm{H}_{2} \mathrm{O}$ ratio seems however quite low in comet $\mathrm{C} / 2002 \mathrm{~V} 1$ and especially in $\mathrm{C} / 2006 \mathrm{P} 1$. The $\mathrm{HDO} / \mathrm{H}_{2} \mathrm{O}$ ratio in comet $\mathrm{C} / 2006 \mathrm{P} 1$, is not well constrained, both $\mathrm{OH}$ and HDO being only marginally detected, but production rates are compatible with the ratio measured in other comets (Bockelée-Morvan et al. 1998; Meier et al. 1998; Jehin et al. $2009, \approx 6 \times 10^{-4}$ ).

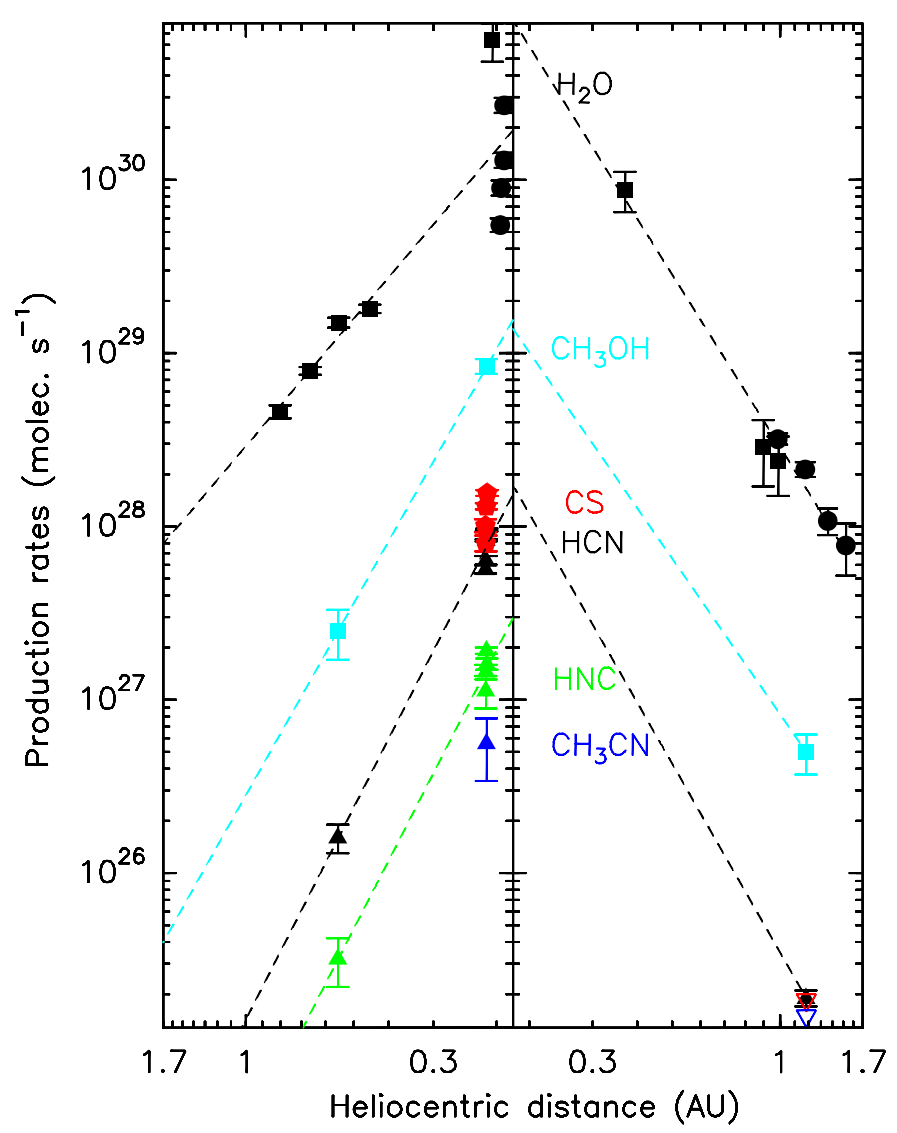

Fig. 18. Molecular production rates in comet C/2002 X5 (KudoFujikawa) pre (left) and post (right) perihelion as a function of heliocentric distance. The water production rates are based either on SOHO or Odin observations (Povich et al. 2003; Biver et al. 2007a) (black dots) or Nançay $\mathrm{OH}$ production rates multiplied by 1.1 (black squares). Dotted lines show the fitted evolutions (see text).

We now turn our discussion to abundances relative to $\mathrm{HCN}$, which are more reliable since HCN was always observed simultaneously. The main observed features are:

- A decrease in the $\mathrm{CH}_{3} \mathrm{OH} / \mathrm{HCN}$ ratio at low $r_{\mathrm{h}} \propto r_{\mathrm{h}}^{0.5}$ is observed for $\mathrm{C} / 2002 \mathrm{X} 5$, confirming the trend observed in comet C/1996 B2 (Hyakutake) (Biver et al. 1999). Using this $r_{\mathrm{h}}^{0.5}$ variation, we infer $\mathrm{CH}_{3} \mathrm{OH} / \mathrm{HCN}$ ratios at $1 \mathrm{AU}$ of 18 and 10 for $\mathrm{C} / 2002 \mathrm{~V} 1$ and $\mathrm{C} / 2006 \mathrm{P} 1$, respectively, which are within the range of abundances measured in comets, though C/2006 P1 belongs to the methanol-poor category (Biver et al. 2002a).

- The CS/HCN ratio varies as $0.35 \times r_{\mathrm{h}}^{-1.0}$. A similar heliocentric dependence $\left(r_{\mathrm{h}}^{-0.8}\right)$ was measured in comet $\mathrm{C} / 1996 \mathrm{~B} 2$ (Biver et al. 1999). In comet 153P, CS/HCN followed $0.55 r_{\mathrm{h}}^{-0.7}$ (Biver et al. 2006a). The puzzling heliocentric variation in the CS/HCN ratio is confirmed down to very low $r_{\mathrm{h}}$.

- Measuring the $\mathrm{HNC} / \mathrm{HCN}$ ratio at small $r_{\mathrm{h}}$ was one of the main objectives of our analysis of these observations. HNC was easily detected in the three comets with an abundance ratio $\mathrm{HNC} / \mathrm{HCN}$ between 0.11 and 0.29 at $r_{\mathrm{h}}<0.26 \mathrm{AU}$. The measurements in comets $\mathrm{C} / 2002$ X5 and C/2002 V1 were included in a previous study of the heliocentric variation of $\mathrm{HNC} / \mathrm{HCN}$ based on a sample of 11 comets at $r_{\mathrm{h}}$ in the range 0.14-1.5 AU (Lis et al. 2008). The $\mathrm{HNC} / \mathrm{HCN}$ sample was fitted by a power law in $r_{\mathrm{h}}^{-2.3}$, with an indication being found of a possible flattening at $r_{\mathrm{h}}<0.5 \mathrm{AU}$. The values 
Table 10. Molecular production rates.

\begin{tabular}{|c|c|c|c|c|c|c|c|c|c|c|}
\hline \multirow{2}{*}{$\begin{array}{l}\text { UT date } \\
{[\mathrm{mm} / \mathrm{dd} . \mathrm{d}]}\end{array}$} & \multirow{2}{*}{$\begin{array}{c}r_{\mathrm{h}} \\
{[\mathrm{AU}]}\end{array}$} & \multicolumn{9}{|c|}{ Production rate in $10^{26}$ molec. $\mathrm{s}^{-1}$} \\
\hline & & $\mathrm{HCN}$ & $\mathrm{HNC}$ & $\mathrm{CH}_{3} \mathrm{CN}$ & $\mathrm{CH}_{3} \mathrm{OH}$ & $\mathrm{H}_{2} \mathrm{CO}^{1}$ & $\mathrm{CO}$ & $\mathrm{CS}$ & $\mathrm{HC}_{3} \mathrm{~N}$ & OCS \\
\hline \multicolumn{11}{|c|}{ C/2002 X5 (Kudo-Fujikawa) (2003) } \\
\hline $01 / 13.61$ & 0.553 & $1.6 \pm 0.3$ & $0.32 \pm 0.10$ & & $25 \pm 8$ & & $<95^{2}$ & & & \\
\hline $01 / 26.47$ & 0.214 & $56.6 \pm 3.0$ & $11.3 \pm 2.4$ & & & & & $101.2 \pm 8.7$ & & \\
\hline $01 / 26.51$ & 0.214 & $63.8 \pm 3.6$ & $14.5 \pm 1.4$ & & & & & $80.1 \pm 8.3$ & & \\
\hline $01 / 26.54$ & 0.213 & $88.7 \pm 5.2$ & $19.2 \pm 0.8$ & $5.6 \pm 2.2$ & $841 \pm 82$ & & & $130.8 \pm 5.3$ & & \\
\hline $01 / 26.58$ & 0.212 & $95.5 \pm 1.6$ & $16.1 \pm 1.2$ & & & & & & & \\
\hline $01 / 26.61$ & 0.212 & & & & & & & $156.0 \pm 6.1$ & $34.8 \pm 5.6$ & \\
\hline $03 / 12.72$ & 1.184 & $0.19 \pm 0.02$ & $<0.064$ & $<0.15$ & $5.0 \pm 1.3$ & & & $<0.19$ & & \\
\hline \multicolumn{11}{|c|}{ C/2002 V1 (NEAT) (2003) } \\
\hline $02 / 16.6$ & 0.135 & $34.0 \pm 1.0$ & $10.0 \pm 0.9$ & $<5.6$ & $220 \pm 60$ & & & $102 \pm 8$ & & $<460$ \\
\hline $02 / 17.5$ & 0.108 & $41.1 \pm 2.5$ & & & $261 \pm 50$ & $<389$ & $<1075$ & $144 \pm 27$ & $<10.3$ & $<581$ \\
\hline \multicolumn{11}{|c|}{ C/2006 P1 (McNaught) (2007) } \\
\hline & & $\mathrm{HCN}$ & HNC & $\mathrm{CH}_{3} \mathrm{CN}$ & $\mathrm{CH}_{3} \mathrm{OH}$ & $\mathrm{H}_{2} \mathrm{CO}^{1}$ & $\mathrm{CO}$ & $\mathrm{CS}$ & $\mathrm{HCOOH}$ & $\mathrm{HDO}$ \\
\hline $01 / 15.65$ & 0.207 & $359 \pm 42$ & & & & & $<37500$ & & & \\
\hline $01 / 16.54$ & 0.228 & $286 \pm 28$ & & & 1450 & 590 & & & $222 \pm 60^{3}$ & 90 \\
\hline $01 / 16.58$ & 0.229 & $242 \pm 23$ & & & \pm 100 & \pm 110 & & & & $\pm 30^{3}$ \\
\hline $01 / 17.55$ & 0.255 & $146 \pm 14$ & $16.7 \pm 2.7$ & $10.6 \pm 4$ & $645 \pm 77$ & & & $217 \pm 33$ & & \\
\hline $01 / 17.58$ & 0.256 & $142 \pm 15$ & & & & & $4290^{3}$ & & & \\
\hline & & & & & & & \pm 1380 & & & \\
\hline
\end{tabular}

Notes. ${ }^{(1)}$ Assuming that $\mathrm{H}_{2} \mathrm{CO}$ comes from an extended source with scale-length $1.75 \times L_{\mathrm{H}_{2} \mathrm{CO}}$. ${ }^{(2)}$ Uncertainty in the tuning: the backend may not have been properly connected to the receiver. ${ }^{(3)}$ Marginal values.

inferred for our three comets do not show a trend for the more productive comets being enriched in $\mathrm{HNC}$, as expected for a formation of HNC by chemical reactions (Rodgers \& Charnley 1998), but rather the opposite. The HNC/HCN ratio in $\mathrm{C} / 2006 \mathrm{P} 1$ is 0.13 , smaller than the value in comet Hale-Bopp at $1 \mathrm{AU}(\approx 0.25)$, this comet being slightly more active than comet Hale-Bopp. Possible origins of HNC in cometary atmospheres are discussed in Rodgers \& Charnley (1998) and Lis et al. (2008). Destruction of HNC by reaction processes possibly takes place at low $r_{\mathrm{h}}$. Small differences in the line shapes between HCN and HNC suggest that HNC might be partly produced in the coma and destroyed further away from the nucleus or be more sensitive to photodissociation than $\mathrm{HCN}$.

Comet C/2006 P1 has compositional similarities with fragments $\mathrm{B}$ and $\mathrm{C}$ of comet $73 \mathrm{P} /$ Schwassmann-Wachmann 3 . All are $\mathrm{CH}_{3} \mathrm{OH}$ and $\mathrm{CO}$-poor, and the $\mathrm{H}_{2} \mathrm{CO} / \mathrm{HCN}, \mathrm{CH}_{3} \mathrm{CN} / \mathrm{HCN}$ ratios are similar (Biver et al. 2006b; Dello Russo et al. 2007b). However, C/2006 P1 is rich in volatile hydrocarbons and in $\mathrm{NH}_{3}$, while $73 \mathrm{P}$ is depleted in these compounds according to Dello Russo et al. (2007a).

Comet $\mathrm{C} / 2002 \mathrm{X} 5$, on the other hand, has a normal $\mathrm{CH}_{3} \mathrm{OH}$ abundance. It is unusually rich in $\mathrm{HC}_{3} \mathrm{~N}$. The $\mathrm{HC}_{3} \mathrm{~N} / \mathrm{HCN}$ ratio is four times higher than in comet Hale-Bopp (Bockelée-Morvan et al. 2000), and still higher than upper limits found in some comets (Biver et al. 2006a). Interestingly, C/2002 X5 belongs to the class of carbon-rich comets (Povich et al. 2003). Finally, the large abundances of $\mathrm{HC}_{3} \mathrm{~N}, \mathrm{HNC}$, and $\mathrm{CH}_{3} \mathrm{CN}$ relative to $\mathrm{HCN}$ in this comet imply that these species are significant contributors to the production of $\mathrm{CN}$ radicals in this comet.

\subsection{Search for refractory molecules}

$\mathrm{SiO}$ was searched through its $J(6-5)$ transition at $260518.020 \mathrm{MHz}$ in comets $\mathrm{C} / 2002 \mathrm{X} 5$ and $\mathrm{C} / 2002 \mathrm{~V} 1$ around perihelion (Tables 2, 3). It was not detected down to about $0.01 \%$ relative to water, assuming thermal equilibrium and a photodissociation rate of $10^{-5} \mathrm{~s}^{-1}$. The same tuning at $260 \mathrm{GHz}$ also allowed us to search for $\mathrm{NaCl} J(20-19)$ line in $\mathrm{C} / 2002 \mathrm{~V} 1$, while the $\mathrm{KCl} J(30-29)$ line was searched for at $230 \mathrm{GHz}$ in $\mathrm{C} / 2002 \mathrm{~V} 1$ and $\mathrm{C} / 2006 \mathrm{P} 1$, in both case without success.

\section{Conclusion}

We have reported on our analysis of millimeter spectroscopic observations of three bright comets (C/2002 X5 (Kudo-Fujikawa), C/2002 V1 (NEAT), and C/2006 P1 (McNaught)) when they were close to the Sun $\left(r_{\mathrm{h}}<0.25 \mathrm{AU}\right)$. Our main challenge has been to cope with ephemeris uncertainties by searching for the peak of brightness in HCN emission using coarse mapping. We have obtained the following results:

- The screening effect in photolytic processes, which affects the distribution of the molecules in the coma, was modeled to determine accurate production rates. This effect is significant, especially for C/2006 P1 where it increases by 40 to $60 \%$ the number of molecules in the coma.

- The various lines have different widths. Velocity variations in the coma were considered to interpret the line shapes. This provided constraints on the CS and HNC scale-lengths.

- The CS photodissociation rate was estimated to $2.5 \pm 0.5 \times$ $10^{-5} \mathrm{~s}^{-1}\left(r_{\mathrm{h}}=1 \mathrm{AU}\right)$, which is compatible with other estimates (Boissier et al. 2007). 
Table 11. Relative abundances.

\begin{tabular}{|c|c|c|c|c|}
\hline \multirow{2}{*}{$\begin{array}{l}\text { Molecule } \\
\left\langle r_{\mathrm{h}}\right\rangle^{1}\end{array}$} & \multicolumn{2}{|c|}{ C/2002 X5 (Kudo-Fujikawa) } & \multirow{2}{*}{$\begin{array}{c}\mathrm{C} / 2002 \text { V1 (NEAT) } \\
0.12\end{array}$} & \multirow{2}{*}{$\begin{array}{c}\text { C/2006 P1 (McNaught) } \\
0.24\end{array}$} \\
\hline & $0.5-1.2$ & 0.21 & & \\
\hline \multicolumn{5}{|c|}{ Abundance relative to water } \\
\hline $\mathrm{HCN}$ & $0.11 \pm 0.02 \%$ & $0.23 \pm 0.02 \%$ & $0.17 \pm 0.01 \%$ & $0.13 \pm 0.02 \%$ \\
\hline $\mathrm{HNC}$ & $0.027-<0.03 \%$ & $0.047 \pm 0.008 \%$ & $0.05 \pm 0.005 \%$ & $0.011 \pm 0.002 \%$ \\
\hline $\mathrm{CH}_{3} \mathrm{CN}$ & & $0.016 \pm 0.006 \%$ & $<0.024 \%$ & $0.008 \pm 0.003 \%$ \\
\hline $\mathrm{HC}_{3} \mathrm{~N}$ & & $0.081 \pm 0.013 \%$ & $<0.045 \%$ & \\
\hline $\mathrm{CH}_{3} \mathrm{OH}$ & $2.3 \pm 0.5 \%$ & $2.4 \pm 0.2 \%$ & $1.1 \pm 0.2 \%$ & $0.6 \pm 0.2 \%$ \\
\hline $\mathrm{H}_{2} \mathrm{CO}$ & & & $<1.95 \%$ & $0.29 \pm 0.06 \%$ \\
\hline $\mathrm{CO}$ & $<8 \%$ & & $<4.3 \%$ & $3 \pm 1 \%$ \\
\hline $\mathrm{HCOOH}$ & & $<0.9 \%$ & & $0.11 \pm 0.03 \%$ \\
\hline HDO & & & & $0.045 \pm 0.015 \%$ \\
\hline CS & $<0.088 \%$ & $0.36 \pm 0.02 \%$ & $0.54 \pm 0.08 \%$ & $0.15 \pm 0.02 \%$ \\
\hline OCS & & & $<1.54 \%$ & \\
\hline SO & & & $<0.81 \%$ & \\
\hline $\mathrm{SiO}$ & & $<0.008 \%$ & $<0.011 \%$ & \\
\hline \multicolumn{5}{|c|}{ Abundance relative to $\mathrm{HCN}$} \\
\hline $\mathrm{HNC}$ & $0.20 \pm 0.07-<0.33$ & $0.198 \pm 0.024$ & $0.29 \pm 0.028$ & $0.114 \pm 0.026$ \\
\hline $\mathrm{CH}_{3} \mathrm{CN}$ & & $0.07 \pm 0.03$ & $<0.14$ & $0.08 \pm 0.03$ \\
\hline $\mathrm{HC}_{3} \mathrm{~N}$ & & $0.36 \pm 0.06$ & $<0.25$ & \\
\hline $\mathrm{CH}_{3} \mathrm{OH}$ & $20 \pm 5$ & $11 \pm 1$ & $6.4 \pm 1.0$ & $5.1 \pm 0.3$ \\
\hline $\mathrm{H}_{2} \mathrm{CO}$ & & & $<9.5$ & $2.2 \pm 0.4$ \\
\hline $\mathrm{CO}$ & $<60$ & & $<26$ & $31 \pm 10$ \\
\hline $\mathrm{HCOOH}$ & & $<4$ & & $0.8 \pm 0.2$ \\
\hline HDO & & & & $0.3 \pm 0.1$ \\
\hline $\mathrm{CS}$ & $<0.96$ & $1.55 \pm 0.17$ & $3.2 \pm 0.3$ & $1.51 \pm 0.24$ \\
\hline OCS & & & $<8.6$ & \\
\hline $\mathrm{SiO}$ & & $<0.04$ & $<0.068$ & \\
\hline
\end{tabular}

- The HNC photodissociation lifetime is found to be slightly shorter (by $\approx 30 \%$ ) than the lifetime of $\mathrm{HCN}$, though this estimate does not consider destruction paths of HNC by chemical reactions.

- The CS/HCN production rate ratio in cometary atmospheres follows a heliocentric dependence $\approx r_{\mathrm{h}}^{-0.8}$ down to $r_{\mathrm{h}}=$ $0.1 \mathrm{AU}$. We rule out artefacts related to uncertainties in CS lifetime. The origin of this variation remains unexplained.

- The $\mathrm{CH}_{3} \mathrm{OH} / \mathrm{HCN}$ production rate ratio decreases with decreasing $r_{\mathrm{h}}$ according to $r_{\mathrm{h}}^{0.5}$.

- $\mathrm{HNC} / \mathrm{HCN}$ ratios are high $(0.11$ to 0.29$)$ in the range $r_{\mathrm{h}}=$ 0.14-0.25 AU, consistent with HNC being a by-product of the thermal degradation of organic grains (Lis et al. 2008). A lower HNC abundance is measured for the more productive comet, possibly indicating destruction of this reactive molecule by chemical processes.

- The $\mathrm{H}_{2} \mathrm{CO} / \mathrm{HCN}$ abundance ratio measured in $\mathrm{C} / 2006 \mathrm{P} 1$ (2.2 at $0.23 \mathrm{AU})$ and $\mathrm{C} / 2002 \mathrm{~V} 1(<9.5$ at $0.12 \mathrm{AU})$ is in the range of values measured in comets at $1 \mathrm{AU}$ from the Sun (Biver et al. 2002a, 2006a, 1.6-10). This possibly rules out $\mathrm{H}_{2} \mathrm{CO}$ production from the thermal degradation of polymers as proposed by Fray et al. (2006).

- The $\mathrm{HC}_{3} \mathrm{~N}$ abundance in $\mathrm{C} / 2002 \mathrm{X} 5$ is higher, by a factor of four or more, than in any of the other eight comets in which it had previously been measured. $\mathrm{HC}_{3} \mathrm{~N}, \mathrm{CH}_{3} \mathrm{CN}$, and $\mathrm{HNC}$ are all significant contributors to the production of $\mathrm{CN}$ radicals in this comet.
- Searches for $\mathrm{SiO}, \mathrm{NaCl}$, and $\mathrm{KCl}$ were unsuccessful. The upper limit set for $\mathrm{SiO}$ is $<10^{-4}$ relative to $\mathrm{H}_{2} \mathrm{O}$.

Acknowledgements. We are grateful to the IRAM staff and to other observers for their assistance during the observations. IRAM is an international institute co-funded by the Centre national de la recherche scientifique (CNRS), the Max Planck Gesellschaft and the Instituto Geográfico Nacional, Spain. This research has been supported by the CNRS and the Programme national de planétologie de l'Institut des sciences de l'univers (INSU).

\section{References}

Biver, N., Bockelée-Morvan, D., Crovisier, J., et al. 1999, AJ, 118, 1850 Biver, N., Bockelée-Morvan, D., Crovisier, J., et al. 2000, AJ, 120, 1554 Biver, N., Bockelée-Morvan, D., Crovisier, J., et al. 2002a, Earth Moon and Planets, 90, 323

Biver, N., Bockelée-Morvan, D., Colom, P., et al. 2002b, Earth Moon and Planets, 90, 5

Biver, N., Bockelée-Morvan, D., Crovisier, J., et al. 2003, BAAS, 35, 968

Biver, N., Bockelée-Morvan, D., Crovisier, J., et al. 2006a, A\&A, 449, 1255

Biver, N., Bockelée-Morvan, D., Boissier, J., et al. 2006b, BAAS, 38, 484

Biver, N., Bockelée-Morvan, D., Crovisier, J., et al. 2007a, Planet. Space Sci., 55,1058

Biver, N., Bockelée-Morvan, D., Boissier, J., et al. 2007b, Icarus, 191, 494 Bockelée-Morvan, D., \& Crovisier, J. 1985, A\&A, 151, 90

Bockelée-Morvan, D., \& Crovisier, J. 1987, in Diversity and Similarity of Comets, ESA SP-78, 235

Bockelée-Morvan, D., Gautier, D., Lis, D. C., et al. 1998, Icarus, 133, 147

Bockelée-Morvan, D., Lis, D. C., Wink, J. E., et al. 2000, A\&A, 353, 1101

Bockelée-Morvan, D., Crovisier, J., Mumma, M. J., \& Weaver, H. A. 2004a, Comets II, 391

Bockelée-Morvan, D., Biver, N., Colom, P., et al. 2004b, Icarus, 167, 113 
Boissier, J, Bockelée-Morvan, D., Biver, N., et al. 2007, A\&A, 475, 1131 Bout, M. V., Lamy, P. L., \& Llebaria, A. 2003, BAAS, 35, 988

Combi, M. R. 2002, Earth Moon and Planets, 89, 73

Combi, M. R., \& Smyth, W. H. 1988, ApJ, 327, 1044

Combi, M. R., Makinen, J. T. T., Lee, Y., Bertaux, J. L., \& Quemerais, E. 2008, BAAS, 40, 413

Crovisier, J. 1989, A\&A, 213, 459

Crovisier, J. 1994, J. Geophys. Res., 99-E2, 3777

Crovisier, J., \& Encrenaz Th. 1983, A\&A, 126, 170

Crovisier, J., Colom, P., Gérard, E., Bockelée-Morvan, D., \& Bourgois, G. 2002, A\&A, 393, 1053

Dello Russo, N., Vervack, R. J., Weaver, H. A., et al. 2007a, Nature, 448, 172

Dello Russo, N., Vervack, R. J., Weaver, H. A., et al. 2007b, BAAS, 38, 522

Despois, D., Gérard, E., Crovisier, J., \& Kazès, I. 1981, A\&A, 99, 320

Fray, N., Bénilan, Y., Biver, N., et al. 2006, Icarus, 184, 239

Fulle, M., Leblanc, F., Harrison, R. A., et al. 2007, ApJ, 661, L93

Gérard, E., Crovisier, J., Colom, P. et al. 1998, Planet. Space Sci., 46, 569

Green, D. W. E. 2007, IAU Circ., 8796

Groussin, O., A'Hearn, M. F., Li, J.-Y., et al. 2007, Icarus, 191, 63
Giorgini, J. D., Yeomans, D. K., Chamberlin, A. B., et al. 1996, BAAS, 28, 1158 Jehin, E., Manfroid, J., Hutsemékers, D., Arpigny, C., \& Zucconi, J.-M. 2009, Earth Moon and Planets, 105, 167

Jorda, L., Crovisier, J., \& Green, D. W. E. 2008, in Asteroids, Comets, Meteors 2008, LPI Contribution 1405, 8046

Lee, L. C. 1984, ApJ, 282, 172

Lee, L. C., \& Suto, M. 1986, Chem. Phys., 110, 161

Lewis, B. R., Vardavas, I. M., \& Carver, J. H. 1983, J. Geophys. Res., 88, 4395

Lis, D. C., Bockelée-Morvan, D., Boissier, J., et al. 2008, ApJ, 675, 931

Marcus, J. N. 2007, Int. Comet Quarterly, 144, 119

McNaught, R. H. 2006, IAU Circ., 8737

Meier, R., Owen, T. C., Matthews, H. E., et al. 1998, Science, 279, 842

Nakano, S. 2002, IAU Circ., 8032

Nee, J. B., \& Lee, L. C. 1985, ApJ, 291, 202

Povich, M. S., Raymond, J. C., Jones, G. H., et al. 2003, Science, 302, 1949

Pravdo, S. 2002, IAU Circ., 8010

Rodgers, S. D., \& Charnley, S. B. 1998, ApJ, 501, L227

Tseng, W.-L., Bockelée-Morvan, D., Crovisier, J., Colom, P., \& Ip, W.-H. 2007, A\&A, 467, 729 
N. Biver et al.: Comets C/2002 X5, C/2002 V1, and C/2006 P1 close to the Sun

Table 2. Molecular observations in comet C/2002 X5 (Kudo-Fujikawa).

\begin{tabular}{|c|c|c|c|c|c|c|c|}
\hline $\begin{array}{l}\text { UT date (2003) } \\
\text { [mm/dd.dd-dd.dd] }\end{array}$ & $\begin{array}{l}\left\langle r_{\mathrm{h}}\right\rangle \\
{[\mathrm{AU}]}\end{array}$ & $\begin{array}{c}\langle\Delta\rangle \\
{[\mathrm{AU}]}\end{array}$ & $\begin{array}{r}\text { Int. time } \\
\text { [min] }\end{array}$ & Line & $\begin{array}{c}\int T_{\mathrm{b}} \mathrm{d} v \\
{\left[\mathrm{~K} \mathrm{~km} \mathrm{~s}^{-1}\right]}\end{array}$ & $\begin{array}{c}\text { Velocity offset } \\
{\left[\mathrm{km} \mathrm{s}^{-1}\right]}\end{array}$ & Offset \\
\hline \multicolumn{8}{|l|}{ IRAM 30-m: } \\
\hline $01 / 13.55-13.66$ & 0.553 & 1.032 & 60 & $\mathrm{HCN}(1-0)$ & $0.119 \pm 0.024$ & $-0.15 \pm 0.25$ & $3.5^{\prime \prime}$ \\
\hline $01 / 13.55-13.66$ & 0.553 & 1.032 & 40 & $\mathrm{HCN}(3-2)$ & $1.405 \pm 0.058$ & $+0.02 \pm 0.08$ & $3.5^{\prime \prime}$ \\
\hline $01 / 26.46-26.46$ & 0.214 & 1.172 & 10 & $\mathrm{HCN}(3-2)$ & $1.075 \pm 0.190$ & $+0.22 \pm 0.22$ & $10^{\prime \prime}$ \\
\hline $01 / 26.47-26.49$ & 0.214 & 1.172 & 10 & $\mathrm{HCN}(3-2)$ & $4.640 \pm 0.190$ & $+0.24 \pm 0.05$ & $6^{\prime \prime}$ \\
\hline $01 / 26.50-26.50$ & 0.214 & 1.172 & 5 & $\mathrm{HCN}(3-2)$ & $6.046 \pm 0.266$ & $+0.29 \pm 0.09$ & $4.5^{\prime \prime}$ \\
\hline $01 / 26.51-26.57$ & 0.213 & 1.172 & 90 & $\operatorname{HCN}(3-2)$ & $14.268 \pm 0.084$ & $+0.24 \pm 0.01$ & $1.0^{\prime \prime}$ \\
\hline $01 / 26.58-26.58$ & 0.213 & 1.172 & 5 & $\mathrm{HCN}(3-2)$ & $11.940 \pm 0.335$ & $+0.30 \pm 0.04$ & $4.0^{\prime \prime}$ \\
\hline $03 / 12.65-12.79$ & 1.184 & 1.096 & 90 & $\mathrm{HCN}(3-2)$ & $0.275 \pm 0.027$ & $-0.16 \pm 0.04$ & $3.0^{\prime \prime}$ \\
\hline $01 / 13.55-13.66$ & 0.553 & 1.032 & 20 & $\mathrm{HNC}(3-2)$ & $0.326 \pm 0.101$ & $+0.36 \pm 0.40$ & $3.5^{\prime \prime}$ \\
\hline $01 / 26.46-26.46$ & 0.214 & 1.172 & 10 & $\mathrm{HNC}(3-2)$ & $<0.501$ & & $13^{\prime \prime}$ \\
\hline $01 / 26.47-26.49$ & 0.214 & 1.172 & 10 & $\mathrm{HNC}(3-2)$ & $0.660 \pm 0.140$ & $+0.40 \pm 0.26$ & $6.8^{\prime \prime}$ \\
\hline $01 / 26.50-26.57$ & 0.213 & 1.172 & 90 & $\mathrm{HNC}(3-2)$ & $2.415 \pm 0.093$ & $+0.33 \pm 0.15$ & $2.8^{\prime \prime}$ \\
\hline $01 / 26.58-26.58$ & 0.213 & 1.172 & 5 & $\mathrm{HNC}(3-2)$ & $1.494 \pm 0.399$ & $+0.02 \pm 0.39$ & $4.4^{\prime \prime}$ \\
\hline $03 / 12.65-12.79$ & 1.184 & 1.096 & 90 & $\mathrm{HNC}(3-2)$ & $<0.106$ & & $3.0^{\prime \prime}$ \\
\hline \multirow[t]{4}{*}{$01 / 26.47-26.63$} & 0.213 & 1.172 & 135 & $\mathrm{CH}_{3} \mathrm{CN}(8,0-7,0)$ & $0.068 \pm 0.016$ & $+0.29 \pm 0.25$ & $1.6^{\prime \prime}$ \\
\hline & & & & $\mathrm{CH}_{3} \mathrm{CN}(8,1-7,1)$ & $0.041 \pm 0.015$ & $-0.08 \pm 0.33$ & \\
\hline & & & & $\mathrm{CH}_{3} \mathrm{CN}(8,2-7,2)$ & $0.028 \pm 0.019$ & & \\
\hline & & & & $\mathrm{CH}_{3} \mathrm{CN}(8,3-7,3)$ & $0.091 \pm 0.019$ & $-0.03 \pm 0.27$ & \\
\hline $03 / 12.65-12.79$ & 1.184 & 1.096 & 90 & $\mathrm{CH}_{3} \mathrm{CN}(8-7)^{1}$ & $<0.054$ & & $3.0^{\prime \prime}$ \\
\hline $01 / 26.60-26.63$ & 0.212 & 1.172 & 25 & $\mathrm{HC}_{3} \mathrm{~N}(28-27)$ & $0.700 \pm 0.112$ & $-0.03 \pm 0.16$ & $1.5^{\prime \prime}$ \\
\hline $01 / 13.55-13.66$ & 0.553 & 1.032 & 60 & $\mathrm{CO}(2-1)$ & $<0.094^{1}$ & & $3.5^{\prime \prime}$ \\
\hline $01 / 26.46-26.46$ & 0.214 & 1.172 & 10 & $\operatorname{CS}(3-2)$ & $0.278 \pm 0.052$ & $+0.45 \pm 0.24$ & $10^{\prime \prime}$ \\
\hline $01 / 26.47-26.49$ & 0.214 & 1.172 & 10 & $\operatorname{CS}(3-2)$ & $0.407 \pm 0.057$ & $+0.23 \pm 0.18$ & $5.5^{\prime \prime}$ \\
\hline $01 / 26.51-26.51$ & 0.214 & 1.172 & 5 & $\operatorname{CS}(3-2)$ & $0.463 \pm 0.048$ & $+0.04 \pm 0.13$ & $1.5^{\prime \prime}$ \\
\hline $01 / 26.52-26.57$ & 0.213 & 1.172 & 85 & $\mathrm{CS}(3-2)$ & $0.744 \pm 0.030$ & $+0.31 \pm 0.05$ & $1.3^{\prime \prime}$ \\
\hline $01 / 26.50-26.58$ & 0.213 & 1.172 & 10 & $\operatorname{CS}(3-2)$ & $0.787 \pm 0.058$ & $+0.10 \pm 0.09$ & $3.7^{\prime \prime}$ \\
\hline $01 / 26.60-26.63$ & 0.212 & 1.172 & 25 & $\operatorname{CS}(3-2)$ & $0.875 \pm 0.034$ & $+0.25 \pm 0.05$ & $1.5^{\prime \prime}$ \\
\hline $03 / 12.65-12.79$ & 1.184 & 1.096 & 135 & $\operatorname{CS}(3-2)$ & $<0.032$ & & $3.0^{\prime \prime}$ \\
\hline $01 / 26.60-26.63$ & 0.212 & 1.172 & 25 & $\mathrm{SiO}(6-5)$ & $<0.516$ & & $1.5^{\prime \prime}$ \\
\hline \multirow[t]{7}{*}{$01 / 13.55-13.66$} & 0.553 & 1.032 & 60 & $\mathrm{CH}_{3} \mathrm{OH}(1,0-1,-1) \mathrm{E}$ & $0.026 \pm 0.013$ & $-0.51 \pm 0.36$ & $3.5^{\prime \prime}$ \\
\hline & & & & $\mathrm{CH}_{3} \mathrm{OH}(2,0-2,-1) \mathrm{E}$ & $0.065 \pm 0.018$ & $+0.58 \pm 0.39$ & \\
\hline & & & & $\mathrm{CH}_{3} \mathrm{OH}(3,0-3,-1) \mathrm{E}$ & $0.099 \pm 0.018$ & $-0.33 \pm 0.21$ & \\
\hline & & & & $\mathrm{CH}_{3} \mathrm{OH}(4,0-4,-1) \mathrm{E}$ & $0.049 \pm 0.018$ & $-0.25 \pm 0.54$ & \\
\hline & & & & $\mathrm{CH}_{3} \mathrm{OH}(5,0-5,-1) \mathrm{E}$ & $0.065 \pm 0.018$ & $+0.03 \pm 0.34$ & \\
\hline & & & & $\mathrm{CH}_{3} \mathrm{OH}(6,0-6,-1) \mathrm{E}$ & $0.047 \pm 0.018$ & $+0.25 \pm 0.38$ & \\
\hline & & & & $\mathrm{CH}_{3} \mathrm{OH}(7,0-7,-1) \mathrm{E}$ & $0.031 \pm 0.018$ & $+0.46 \pm 0.64$ & \\
\hline \multirow[t]{7}{*}{$01 / 26.47-26.63$} & 0.213 & 1.172 & 135 & $\mathrm{CH}_{3} \mathrm{OH}(1,0-1,-1) \mathrm{E}$ & $0.072 \pm 0.027$ & $-0.16 \pm 0.38$ & $3.0^{\prime \prime}$ \\
\hline & & & & $\mathrm{CH}_{3} \mathrm{OH}(2,0-2,-1) \mathrm{E}$ & $0.101 \pm 0.030$ & $+0.75 \pm 0.41$ & \\
\hline & & & & $\mathrm{CH}_{3} \mathrm{OH}(3,0-3,-1) \mathrm{E}$ & $0.142 \pm 0.028$ & $-0.28 \pm 0.22$ & \\
\hline & & & & $\mathrm{CH}_{3} \mathrm{OH}(4,0-4,-1) \mathrm{E}$ & $0.113 \pm 0.030$ & $-0.11 \pm 0.31$ & \\
\hline & & & & $\mathrm{CH}_{3} \mathrm{OH}(5,0-5,-1) \mathrm{E}$ & $0.197 \pm 0.028$ & $+0.30 \pm 0.17$ & \\
\hline & & & & $\mathrm{CH}_{3} \mathrm{OH}(6,0-6,-1) \mathrm{E}$ & $0.197 \pm 0.029$ & $+0.13 \pm 0.17$ & \\
\hline & & & & $\mathrm{CH}_{3} \mathrm{OH}(7,0-7,-1) \mathrm{E}$ & $0.214 \pm 0.028$ & $-0.10 \pm 0.15$ & \\
\hline \multirow[t]{8}{*}{$03 / 12.65-12.79$} & 1.184 & 1.096 & 135 & $\mathrm{CH}_{3} \mathrm{OH}(1,0-1,-1) \mathrm{E}$ & $0.042 \pm 0.012$ & $+0.24 \pm 0.12$ & $3.0^{\prime \prime}$ \\
\hline & & & & $\mathrm{CH}_{3} \mathrm{OH}(2,0-2,-1) \mathrm{E}$ & $0.024 \pm 0.014$ & & \\
\hline & & & & $\mathrm{CH}_{3} \mathrm{OH}(3,0-3,-1) \mathrm{E}$ & $0.011 \pm 0.013$ & & \\
\hline & & & & $\mathrm{CH}_{3} \mathrm{OH}(4,0-4,-1) \mathrm{E}$ & $0.015 \pm 0.014$ & & \\
\hline & & & & $\mathrm{CH}_{3} \mathrm{OH}(5,0-5,-1) \mathrm{E}$ & $0.043 \pm 0.016$ & $-0.12 \pm 0.15$ & \\
\hline & & & & $\mathrm{CH}_{3} \mathrm{OH}(6,0-6,-1) \mathrm{E}$ & $0.036 \pm 0.012$ & $-0.03 \pm 0.12$ & \\
\hline & & & & $\mathrm{CH}_{3} \mathrm{OH}(7,0-7,-1) \mathrm{E}$ & $0.027 \pm 0.012$ & $-0.03 \pm 0.16$ & \\
\hline & & & & sum of 7 lines & $0.150 \pm 0.037$ & $-0.01 \pm 0.09$ & \\
\hline
\end{tabular}

Notes. ${ }^{(1)}$ Sum of $\mathrm{CH}_{3} \mathrm{CN}(8,0-7,0), \mathrm{CH}_{3} \mathrm{CN}(8,1-7,1)$ and $\mathrm{CH}_{3} \mathrm{CN}(8,2-7,2)$ lines. 
Table 3. Molecular observations in comet C/2002 V1 (NEAT).

\begin{tabular}{|c|c|c|c|c|c|c|c|}
\hline $\begin{array}{l}\text { UT date (2003) } \\
\text { [mm/dd.dd-dd.dd] }\end{array}$ & $\begin{array}{c}\left\langle r_{\mathrm{h}}\right\rangle \\
{[\mathrm{AU}]}\end{array}$ & $\begin{array}{c}\langle\Delta\rangle \\
{[\mathrm{AU}]}\end{array}$ & $\begin{array}{r}\text { Int. time } \\
\text { [min] }\end{array}$ & Line & $\underset{\left[\mathrm{K} \mathrm{km} \mathrm{s}^{-1}\right]}{\int T_{\mathrm{b}} \mathrm{d} v}$ & $\begin{array}{c}\text { Velocity offset } \\
{\left[\mathrm{km} \mathrm{s}^{-1}\right]}\end{array}$ & Offset \\
\hline \multicolumn{8}{|l|}{ IRAM 30-m: } \\
\hline \multirow[t]{2}{*}{ 02/16.49-16.59 } & 0.136 & 0.978 & 50 & $\mathrm{HCN}(3-2)$ & $4.146 \pm 0.061$ & $-0.02 \pm 0.03$ & $1.8^{\prime \prime}$ \\
\hline & 0.136 & 0.978 & 19 & $\mathrm{HCN}(3-2)$ & $2.173 \pm 0.112$ & $-0.01 \pm 0.11$ & $5.1^{\prime \prime}$ \\
\hline $02 / 17.48-17.52$ & 0.108 & 0.985 & 19 & $\mathrm{HCN}(3-2)$ & $3.558 \pm 0.069$ & $+0.01 \pm 0.04$ & $1.8^{\prime \prime}$ \\
\hline $02 / 17.48-17.50$ & 0.109 & 0.985 & 9 & $\mathrm{HCN}(3-2)$ & $1.819 \pm 0.140$ & $-0.18 \pm 0.17$ & $5.7^{\prime \prime}$ \\
\hline 02/17.55-17.66 & 0.106 & 0.987 & 85 & $\mathrm{HCN}(1-0)$ & $0.116 \pm 0.021$ & $+0.06 \pm 0.32$ & $1.8^{\prime \prime}$ \\
\hline 02/16.49-16.59 & 0.135 & 0.978 & 29 & $\mathrm{HNC}(3-2)$ & $0.648 \pm 0.113$ & $+0.09 \pm 0.35$ & $5.5^{\prime \prime}$ \\
\hline $02 / 16.49-16.66$ & 0.134 & 0.978 & 85 & $\mathrm{HNC}(3-2)$ & $0.914 \pm 0.060$ & $+0.25 \pm 0.13$ & $2.8^{\prime \prime}$ \\
\hline 02/16.49-16.59 & 0.135 & 0.978 & 27 & $\operatorname{CS}(3-2)$ & $0.242 \pm 0.054$ & $+0.57 \pm 0.42$ & $5.5^{\prime \prime}$ \\
\hline 02/16.49-16.66 & 0.134 & 0.978 & 87 & $\mathrm{CS}(3-2)$ & $0.336 \pm 0.026$ & $+0.05 \pm 0.13$ & $2.8^{\prime \prime}$ \\
\hline $02 / 17.48-17.52$ & 0.108 & 0.985 & 22 & $\mathrm{CS}(3-2)$ & $0.373 \pm 0.046$ & $-0.34 \pm 0.21$ & $1.7^{\prime \prime}$ \\
\hline $02 / 17.48-17.50$ & 0.109 & 0.985 & 6 & $\mathrm{CS}(3-2)$ & $0.180 \pm 0.085$ & & $5.6^{\prime \prime}$ \\
\hline $02 / 16.49-17.50$ & 0.130 & 0.980 & 22 & $\mathrm{CH}_{3} \mathrm{CN}(8-7)^{1}$ & $<0.126$ & & $2.5^{\prime \prime}$ \\
\hline 02/17.61-17.66 & 0.106 & 0.987 & 35 & $\mathrm{CO}(2-1)$ & $<0.161$ & & $2.8^{\prime \prime}$ \\
\hline \multirow[t]{3}{*}{$02 / 16.54-17.66$} & 0.120 & 0.982 & 80 & OCS $(12-11)$ & $<0.029$ & & $2.1^{\prime \prime}$ \\
\hline & & & & $\mathrm{HC}_{3} \mathrm{~N}(16-15)$ & $<0.031$ & & $2.1^{\prime \prime}$ \\
\hline & & & & $\mathrm{H}_{2} \mathrm{CO}\left(2_{02}-1_{01}\right)$ & $0.032 \pm 0.012$ & & $2.1^{\prime \prime}$ \\
\hline $02 / 17.55-17.60$ & 0.107 & 0.986 & 50 & $\mathrm{H}_{2} \mathrm{CO}\left(3_{12}-2_{11}\right)$ & $<0.136$ & & $1.0^{\prime \prime}$ \\
\hline \multirow[t]{6}{*}{$02 / 16.60-17.60$} & 0.120 & 0.982 & 107 & $\mathrm{CH}_{3} \mathrm{OH}(3,3-3,2) \mathrm{A}^{ \pm 2}$ & $0.072 \pm 0.045$ & & $1.8^{\prime \prime}$ \\
\hline & & & & $\mathrm{CH}_{3} \mathrm{OH}(4,3-4,2) \mathrm{A}^{ \pm}$ & $0.213 \pm 0.046$ & $+0.20 \pm 0.35$ & \\
\hline & & & & $\mathrm{CH}_{3} \mathrm{OH}(5,3-5,2) \mathrm{A}^{ \pm}$ & $0.092 \pm 0.044$ & & \\
\hline & & & & $\mathrm{CH}_{3} \mathrm{OH}(6,3-6,2) \mathrm{A}^{ \pm}$ & $0.182 \pm 0.047$ & $+0.31 \pm 0.48$ & \\
\hline & & & & $\mathrm{CH}_{3} \mathrm{OH}(7,3-7,2) \mathrm{A}^{ \pm}$ & $0.198 \pm 0.041$ & $-0.28 \pm 0.29$ & \\
\hline & & & & $\mathrm{CH}_{3} \mathrm{OH}(8,3-8,2) \mathrm{A}^{ \pm}$ & $0.057 \pm 0.041$ & & \\
\hline 02/16.60-17.60 & 0.120 & 0.982 & 107 & $\mathrm{SO}\left(5_{6}-4_{5}\right)$ & $<0.071$ & & $1.8^{\prime \prime}$ \\
\hline 02/17.61-17.66 & 0.106 & 0.987 & 35 & $\mathrm{SiO}(6-5)$ & $<0.190$ & & $1.7^{\prime \prime}$ \\
\hline
\end{tabular}

Notes. ${ }^{(1)}$ Sum of $\mathrm{CH}_{3} \mathrm{CN}(8,0-7,0), \mathrm{CH}_{3} \mathrm{CN}(8,1-7,1), \mathrm{CH}_{3} \mathrm{CN}(8,2-7,2)$ and $\mathrm{CH}_{3} \mathrm{CN}(8,3-7,3)$ lines. ${ }^{(2)}$ Sums of twin lines. 
Table 4. Molecular observations in comet C/2006 P1 (Mc Naught).

\begin{tabular}{|c|c|c|c|c|c|c|c|}
\hline $\begin{array}{c}\text { UT date (2007) } \\
\text { [mm/dd.dd-dd.dd] }\end{array}$ & $\begin{array}{l}\left\langle r_{\mathrm{h}}\right\rangle \\
{[\mathrm{AU}]}\end{array}$ & $\begin{array}{c}\langle\Delta\rangle \\
{[\mathrm{AU}]}\end{array}$ & $\begin{array}{r}\text { Int. time } \\
{[\mathrm{min}]}\end{array}$ & Line & $\begin{array}{c}\int T_{\mathrm{b}} \mathrm{d} v \\
{\left[\mathrm{~K} \mathrm{~km} \mathrm{~s}^{-1}\right]}\end{array}$ & $\begin{array}{c}\text { Velocity offset } \\
{\left[\mathrm{km} \mathrm{s}^{-1}\right]}\end{array}$ & Offset \\
\hline \multirow{6}{*}{$\begin{array}{c}\text { IRAM 30-m: } \\
01 / 15.65\end{array}$} & & & & & & & \\
\hline & 0.207 & 0.817 & 0.1 & $\mathrm{HCN}(3-2)$ & $83.74 \pm 7.63$ & $-0.27 \pm 0.16$ & $2.6^{\prime \prime}$ \\
\hline & 0.207 & 0.817 & 0.2 & $\mathrm{HCN}(3-2)$ & $57.66 \pm 5.82$ & $+0.33 \pm 0.18$ & $5.0^{\prime \prime}$ \\
\hline & 0.207 & 0.817 & 2.0 & $\mathrm{HCN}(3-2)$ & $31.78 \pm 3.07$ & $+0.40 \pm 0.18$ & 7.4" \\
\hline & 0.207 & 0.817 & 0.3 & $\mathrm{HCN}(3-2)$ & $22.89 \pm 5.08$ & $-0.21 \pm 0.38$ & $8.9^{\prime \prime}$ \\
\hline & 0.207 & 0.817 & 0.8 & $\mathrm{HCN}(3-2)$ & $13.76 \pm 3.32$ & $+0.33 \pm 0.44$ & $12.1^{\prime \prime}$ \\
\hline $01 / 16.53$ & 0.228 & 0.821 & 8.0 & $\mathrm{HCN}(3-2)$ & $48.45 \pm 0.42$ & $-0.07 \pm 0.02$ & $4.9^{\prime \prime}$ \\
\hline $01 / 16.54$ & 0.228 & 0.821 & 8.0 & $\mathrm{HCN}(3-2)$ & $63.65 \pm 0.39$ & $-0.09 \pm 0.01$ & $2.1^{\prime \prime}$ \\
\hline $01 / 16.55$ & 0.228 & 0.821 & 20.0 & $\mathrm{HCN}(3-2)$ & $37.47 \pm 0.26$ & $-0.06 \pm 0.02$ & $6.5^{\prime \prime}$ \\
\hline $01 / 16.54$ & 0.228 & 0.821 & 4.0 & $\mathrm{HCN}(3-2)$ & $27.28 \pm 0.57$ & $-0.03 \pm 0.05$ & $8.2^{\prime \prime}$ \\
\hline $01 / 16.58$ & 0.229 & 0.822 & 12.0 & $\mathrm{HCN}(3-2)$ & $47.89 \pm 0.28$ & $-0.03 \pm 0.01$ & $4.7^{\prime \prime}$ \\
\hline $01 / 16.59$ & 0.229 & 0.822 & 8.0 & $\mathrm{HCN}(3-2)$ & $16.60 \pm 0.33$ & $+0.04 \pm 0.05$ & $9.3^{\prime \prime}$ \\
\hline $01 / 17.55$ & 0.255 & 0.832 & 2.0 & $\mathrm{HCN}(3-2)$ & $35.91 \pm 0.59$ & $-0.05 \pm 0.04$ & $3.3^{\prime \prime}$ \\
\hline $01 / 17.54$ & 0.255 & 0.832 & 10.0 & $\mathrm{HCN}(3-2)$ & $21.81 \pm 0.28$ & $-0.02 \pm 0.03$ & $5.3^{\prime \prime}$ \\
\hline $01 / 17.56$ & 0.255 & 0.833 & 31.0 & $\mathrm{HCN}(3-2)$ & $15.58 \pm 0.16$ & $+0.04 \pm 0.02$ & 7.1" \\
\hline $01 / 17.55$ & 0.255 & 0.832 & 5.0 & $\mathrm{HCN}(3-2)$ & $14.44 \pm 0.40$ & $-0.02 \pm 0.06$ & $8.5^{\prime \prime}$ \\
\hline $01 / 17.58$ & 0.256 & 0.833 & 20.0 & $\mathrm{HCN}(3-2)$ & $6.72 \pm 0.22$ & $-0.04 \pm 0.07$ & $10.7^{\prime \prime}$ \\
\hline $01 / 17.58$ & 0.256 & 0.833 & 12.0 & $\mathrm{HCN}(3-2)$ & $5.69 \pm 0.27$ & $-0.06 \pm 0.11$ & $12.4^{\prime \prime}$ \\
\hline $01 / 16.54$ & 0.228 & 0.821 & 20.0 & $\mathrm{HCN}(1-0)$ & $1.723 \pm 0.057$ & $+0.16 \pm 0.05$ & $3.9^{\prime \prime}$ \\
\hline $01 / 16.55$ & 0.228 & 0.821 & 16.0 & $\mathrm{HCN}(1-0)$ & $1.505 \pm 0.066$ & $+0.02 \pm 0.06$ & $6.8^{\prime \prime}$ \\
\hline $01 / 16.54$ & 0.228 & 0.821 & 4.0 & $\mathrm{HCN}(1-0)$ & $1.574 \pm 0.131$ & $-0.13 \pm 0.11$ & $8.1^{\prime \prime}$ \\
\hline $01 / 16.59$ & 0.229 & 0.822 & 12.0 & $\mathrm{HCN}(1-0)$ & $1.920 \pm 0.031$ & $-0.01 \pm 0.02$ & $4.8^{\prime \prime}$ \\
\hline $01 / 16.59$ & 0.229 & 0.822 & 8.0 & $\mathrm{HCN}(1-0)$ & $1.261 \pm 0.037$ & $-0.08 \pm 0.03$ & $10.2^{\prime \prime}$ \\
\hline $01 / 17.55$ & 0.255 & 0.832 & 2.0 & $\mathrm{HNC}(3-2)$ & $4.05 \pm 0.55$ & $-0.06 \pm 0.18$ & $3.7^{\prime \prime}$ \\
\hline $01 / 17.54$ & 0.255 & 0.832 & 9.0 & $\mathrm{HNC}(3-2)$ & $3.16 \pm 0.24$ & $+0.03 \pm 0.09$ & $4.7^{\prime \prime}$ \\
\hline $01 / 17.56$ & 0.255 & 0.833 & 23.0 & $\mathrm{HNC}(3-2)$ & $1.53 \pm 0.16$ & $+0.11 \pm 0.12$ & $6.7^{\prime \prime}$ \\
\hline $01 / 17.54$ & 0.255 & 0.832 & 14.0 & $\mathrm{HNC}(3-2)$ & $1.52 \pm 0.20$ & $+0.13 \pm 0.16$ & $9.1^{\prime \prime}$ \\
\hline $01 / 17.54$ & 0.255 & 0.832 & 8.0 & $\mathrm{HNC}(3-2)$ & $0.52 \pm 0.26$ & & $11.5^{\prime \prime}$ \\
\hline $01 / 17.55$ & 0.255 & 0.832 & 2.0 & $\mathrm{CS}(3-2)$ & $2.84 \pm 0.20$ & $+0.07 \pm 0.08$ & $3.4^{\prime \prime}$ \\
\hline $01 / 17.54$ & 0.255 & 0.832 & 8.0 & $\mathrm{CS}(3-2)$ & $2.47 \pm 0.10$ & $-0.04 \pm 0.04$ & $4.7^{\prime \prime}$ \\
\hline $01 / 17.56$ & 0.255 & 0.833 & 24.0 & $\mathrm{CS}(3-2)$ & $1.53 \pm 0.06$ & $-0.03 \pm 0.04$ & $6.8^{\prime \prime}$ \\
\hline $01 / 17.54$ & 0.255 & 0.832 & 13.0 & $\operatorname{CS}(3-2)$ & $1.17 \pm 0.08$ & $-0.09 \pm 0.08$ & $9.1^{\prime \prime}$ \\
\hline $01 / 17.54$ & 0.255 & 0.832 & 9.0 & $\mathrm{CS}(3-2)$ & $1.01 \pm 0.09$ & $+0.11 \pm 0.10$ & $11.4^{\prime \prime}$ \\
\hline \multirow{5}{*}{$01 / 17.51-17.58$} & 0.255 & 0.832 & 47 & $\mathrm{CH}_{3} \mathrm{CN}(8,0-7,0)$ & $0.148 \pm 0.040$ & $+0.45 \pm 0.20$ & $6.9^{\prime \prime}$ \\
\hline & & & & $\mathrm{CH}_{3} \mathrm{CN}(8,1-7,1)$ & $0.080 \pm 0.044$ & $-0.60 \pm 0.47$ & \\
\hline & & & & $\mathrm{CH}_{3} \mathrm{CN}(8,2-7,2)$ & $0.004 \pm 0.039$ & & \\
\hline & & & & $\mathrm{CH}_{3} \mathrm{CN}(8,3-7,3)$ & $0.104 \pm 0.042$ & $-1.01 \pm 0.62$ & \\
\hline & & & & Sum of the 4 lines & $0.334 \pm 0.083$ & & \\
\hline \multirow[t]{7}{*}{$01 / 16.52-16.60$} & 0.228 & 0.821 & 48 & $\mathrm{CH}_{3} \mathrm{OH}(1,0-1,-1) \mathrm{E}$ & $0.203 \pm 0.050$ & & $4.9^{\prime \prime}$ \\
\hline & & & & $\mathrm{CH}_{3} \mathrm{OH}(2,0-2,-1) \mathrm{E}$ & $0.160 \pm 0.047$ & $-0.52 \pm 0.44$ & \\
\hline & & & & $\mathrm{CH}_{3} \mathrm{OH}(3,0-3,-1) \mathrm{E}$ & $0.309 \pm 0.050$ & & \\
\hline & & & & $\mathrm{CH}_{3} \mathrm{OH}(4,0-4,-1) \mathrm{E}$ & $0.327 \pm 0.048$ & $-0.06 \pm 0.21$ & \\
\hline & & & & $\mathrm{CH}_{3} \mathrm{OH}(5,0-5,-1) \mathrm{E}$ & $0.305 \pm 0.047$ & $+0.14 \pm 0.22$ & \\
\hline & & & & $\mathrm{CH}_{3} \mathrm{OH}(6,0-6,-1) \mathrm{E}$ & $0.347 \pm 0.047$ & $-0.05 \pm 0.20$ & \\
\hline & & & & $\mathrm{CH}_{3} \mathrm{OH}(7,0-7,-1) \mathrm{E}$ & $0.297 \pm 0.042$ & $-0.24 \pm 0.20$ & \\
\hline $01 / 16.54-16.60$ & 0.228 & 0.821 & 8 & $\mathrm{CH}_{3} \mathrm{OH}(J, 0-J,-1) \mathrm{E}^{1}$ & $0.857 \pm 0.198$ & $-0.60 \pm 0.35$ & $8.9^{\prime \prime}$ \\
\hline \multirow[t]{8}{*}{$01 / 17.51-17.58$} & 0.255 & 0.832 & 48 & $\mathrm{CH}_{3} \mathrm{OH}(1,0-1,-1) \mathrm{E}$ & $0.024 \pm 0.035$ & & $6.7^{\prime \prime}$ \\
\hline & & & & $\mathrm{CH}_{3} \mathrm{OH}(2,0-2,-1) \mathrm{E}$ & $-0.021 \pm 0.039$ & & \\
\hline & & & & $\mathrm{CH}_{3} \mathrm{OH}(3,0-3,-1) \mathrm{E}$ & $0.081 \pm 0.035$ & & \\
\hline & & & & $\mathrm{CH}_{3} \mathrm{OH}(4,0-4,-1) \mathrm{E}$ & $0.028 \pm 0.042$ & $+0.64 \pm 0.60$ & \\
\hline & & & & $\mathrm{CH}_{3} \mathrm{OH}(5,0-5,-1) \mathrm{E}$ & $0.095 \pm 0.040$ & $-0.47 \pm 0.46$ & \\
\hline & & & & $\mathrm{CH}_{3} \mathrm{OH}(6,0-6,-1) \mathrm{E}$ & $0.103 \pm 0.045$ & $-0.17 \pm 0.47$ & \\
\hline & & & & $\mathrm{CH}_{3} \mathrm{OH}(7,0-7,-1) \mathrm{E}$ & $0.082 \pm 0.040$ & $-0.55 \pm 0.40$ & \\
\hline & & & & $\mathrm{CH}_{3} \mathrm{OH}(J, 0-J,-1) \mathrm{E}^{1}$ & $0.380 \pm 0.079$ & $-0.40 \pm 0.29$ & $6.7^{\prime \prime}$ \\
\hline $01 / 16.52-16.60$ & 0.228 & 0.821 & 60 & $\mathrm{H}_{2} \mathrm{CO}\left(3_{12}-2_{11}\right)$ & $0.334 \pm 0.050$ & $-0.18 \pm 0.20$ & $6.1^{\prime \prime}$ \\
\hline $01 / 16.52-16.59$ & 0.228 & 0.821 & 36 & $\operatorname{HDO}\left(3_{12}-2_{11}\right)$ & $0.227 \pm 0.064$ & $-0.68 \pm 0.40$ & $4.2^{\prime \prime}$ \\
\hline $01 / 15.60$ & 0.207 & 0.817 & 5.0 & $\mathrm{CO}(2-1)$ & $<2.31$ & & $12.1^{\prime \prime}$ \\
\hline $01 / 17.59-17.61$ & 0.256 & 0.833 & 24 & $\mathrm{CO}(2-1)$ & $0.30 \pm 0.09$ & $-0.07 \pm 0.43$ & $11.2^{\prime \prime}$ \\
\hline $01 / 17.59-17.61$ & 0.256 & 0.833 & 24 & $\mathrm{HCO}+(1-0)$ & $0.36 \pm 0.05$ & $-0.05 \pm 0.27$ & $10.9^{\prime \prime}$ \\
\hline
\end{tabular}

Notes. ${ }^{(1)}$ Sum of $\mathrm{CH}_{3} \mathrm{OH}$ lines $J, K=(4,0-4,-1) \mathrm{E},(5,0-5,-1) \mathrm{E},(6,0-6,-1) \mathrm{E}$ and $(7,0-7,-1) \mathrm{E}$. 